\title{
Silencing of Putative Cytokinin Receptor Histidine Kinase1 Inhibits Both Inception and Differentiation of Root Nodules in Arachis hypogaea
}

\author{
Anindya Kundu and Maitrayee DasGupta ${ }^{\dagger}$ \\ Department of Biochemistry, University of Calcutta, Kolkata 700019, India
}

Accepted 4 September 2017.

\begin{abstract}
Rhizobia-legume interaction activates the SYM pathway that recruits cytokinin signaling for induction of nodule primordia in the cortex. In Arachis hypogaea, bradyrhizobia invade through natural cracks developed in the lateral root base and are directly endocytosed in the cortical cells to generate the nodule primordia. To unravel the role of cytokinin signaling in A. hypogaea, RNA-interference (RNAi) of cytokinin receptor histidine-kinase1 (AhHK1) was done. AhHK1-RNAi downregulated the expression of type-A response regulators such as $A h R R 5$ and $A h R R 3$ along with several symbiotic genes, indicating that both cytokinin signaling and the SYM pathway were affected. Accordingly, there was a drastic downregulation of nodulation in AhHK1-RNAi roots and the nodules that developed were ineffective. These nodules were densely packed, with infected cells having a higher nucleo-cytoplasmic ratio and distinctively high mitotic index, where the rod-shaped rhizobia failed to differentiate into bacteroids within spherical symbiosomes. In accordance with the proliferating state, expression of a mitotic-cyclin $A h C y c B 2.1$ was higher in $A h H K 1$ RNA $i$ nodules, whereas expression of a retinoblastoma-related $(A h R B R)$ nodule that restrains proliferation was lower. Also, higher expression of the meristem maintenance factor WUSCHELRELATED HOMEOBOX5 correlated with the undifferentiated state of $A h H K 1-R N A i$ nodules. Our results suggest that AhHK1-mediated cytokinin signaling is important for both inception and differentiation during nodule development in A. hypogaea.
\end{abstract}

A compatible rhizobia-legume interaction activates the Nodfactor-dependent SYM pathway that leads to a local accumulation of cytokinin as a trigger toward the induction of a de novo meristem in the root cortical cells (Frugier et al. 2008). Both exogenous cytokinin and rhizobia engineered to secrete transzeatin are able to initiate nodule primordium (Cooper and Long 1994; Heckmann et al. 2011; Podlesakova et al. 2013). Cytokinin signaling causes local auxin accumulation at the site of incipient nodule primordia by modulating the expression of auxin transporters (Ng et al. 2015; Plet et al. 2011). Together, these phytohormonal signals and the SYM pathway reprogram the cortical

Sequence data for $A h H K 1$ is available under accession number of KT153625.

${ }^{\dagger}$ Corresponding author: M. DasGupta; E-mail: maitrayee_d@hotmail.com

*The $e$-Xtra logo stands for "electronic extra" and indicates that six supplementary figures and three supplementary tables are published online.

(C) 2018 The American Phytopathological Society cells and regulate their division, ultimately building a nodule primordium for the endocytic accommodation of the symbionts (Mathesius et al. 2000a; Suzaki et al. 2012).

Cytokinin is sensed by the extracellular cyclase/histidine kinase-associated sensing extracellular (CHASE) domain present in the cytokinin response1 (MtCRE1) and Lotus histidine kinase1 (LHK1) transmembrane receptors in Medicago truncatula and Lotus japonicus, respectively (Gonzalez-Rizzo et al. 2006; Tirichine et al. 2007). Loss-of-function mutations of LHK1 (lhkl-1 allele, formerly known as hitl) and MtCRE1 (cre1-1/2) lead to a strong reduction in nodulation (Murray et al. 2007; Plet et al. 2011), suggesting that cytokinin-dependent phosphorelay through these receptor histidine kinases (HK) is essential for nodule organogenesis. On the other hand, gainof-function mutation of LHK1 (snf2) is sufficient to induce nodule primordia in the absence of rhizobia, demonstrating that cytokinin signaling is sufficient to initiate this developmental process (Tirichine et al. 2007). Cytokinin oxidase or dehydrogenase expressed during nodule development restricts the level of active cytokinin for balancing its positive role in nodule organogenesis with its negative effect on rhizobial infection (Reid et al. 2016). Downstream of cytokinin receptors, a histidylaspartyl multistep phosphorelay is initiated, leading to the activation of the type-B response regulators (RR) which, in turn, regulate the primary response genes such as the type-A RR (To et al. 2007). Several type-A RR such as MtRR4, LjRR5, and $M T R R 9$ are induced during nodulation and coordinate the downstream functional responses (Gonzalez-Rizzo et al. 2006; Op den Camp et al. 2011; Tirichine et al. 2007).

Several evidences suggest a hierarchical organization of the Nod factor-dependent activation of the SYM-Pathway and cytokinin signaling for the development of root nodule symbiosis (RNS). For example, spontaneous nodule formation is induced by constitutive activation of Nod factor signaling or cytokinin signaling (Gleason et al. 2006; Saha et al. 2014; Tirichine et al. 2006, 2007). Constitutive activation of cytokinin signaling (snf2) leads to spontaneous nodulation in the absence of a functional SYM pathway but constitutive activation of a SYM pathway (snfl) is unable to trigger the same in the absence of cytokinin signaling (Madsen et al. 2010). Recently, the Nod factors have been demonstrated to induce the accumulation of cytokinin, confirming its precedence to cytokinin signaling (Held et al. 2014; van Zeijl et al. 2015). Apart from the hierarchical organization, evidence also indicates a crosstalk between the SYM pathway and the cytokinin signaling. For example, cytokinin RRs are induced during the Nod factordependent symbiotic interactions (Gonzalez-Rizzo et al. 2006; Murray et al. 2007; Plet et al. 2011). In addition, cytokinin signaling activates several symbiosis-responsive transcription 
factors (TF) such as nodule inception (NIN) and NODULATION SIGNALING PATHWAY 1 and 2 (NSP1 and NSP2), ERF required for nodulation (ERN1), nuclear factor Y (NF-YA1, formerly known as Hap2), and early nodulation 40 (ENOD40) (Charon et al. 1997; Crespi et al. 1994; Gonzalez-Rizzo et al. 2006; Heckmann et al. 2011; Mathesius et al. 2000b; Murray et al. 2007; Op den Camp et al. 2011; Plet et al. 2011; Smit et al. 2005; Tirichine et al. 2007) Finally, apart from being the key endogenous signal for nodule development and differentiation (Plet et al. 2011), cytokinin also maintains the homeostasis of the symbiotic interaction by limiting the extent of additional infection at the root epidermis, indicating that the SYM pathway and cytokinin signaling are connected through feedback loops (Miri et al. 2016).

In M. truncatula or L. japonicus, the epidermal and the cortical processes are spatially and temporally coordinated to ensure rhizobial accommodation from the invading infection threads in the subtending nodule primordia in the cortex (Miri et al. 2016; Oldroyd 2013; Popp and Ott 2011; Saha et al. 2016). In both of these legumes, endoreduplication of host cells is found necessary for bacterial infection and differentiation of nodules whereas, in Medicago spp., the symbionts also endoreduplicate to mature into functional nitrogen-fixing symbiosomes (González-Sama et al. 2006; Mergaert et al. 2006; Truchet 1978). In approximately $25 \%$ of the legume species that are found mainly in tropical and warm temperate areas, rhizobial invasion does not involve the formation of infection threads (Sprent and James 2007). Examples are Aeschynomene legumes such as Arachis hypogaea, where rhizobia invade through natural annular cracks developed in the lateral root base and are directly endocytosed in the cortical cells to generate a nodule primordia (Bal et al. 1989; Chandler 1978). The rhizobia-infected cells within the nodule primordia divide repeatedly to form a typical aeschynomenoid type of determinate nodule characterized by the absence of uninfected cells in the central infection zone (IZ) (Boogerd and Rossum 1997). After the host cells cease to divide in aeschynomenoid nodules, the rod-shaped rhizobia differentiate into bacteroids within large, spherical nitrogen-fixing symbiosomes (Oono and Denison 2010). As seen with inverted repeat-lacking clade legumes such as $M$. truncatula, this differentiation is noted to be associated with endoreduplication (Czernic et al. 2015).

To unravel the role of cytokinin signaling in A. hypogaea, RNA-interference (RNAi) of cytokinin receptor histidinekinase1 $(A h H K 1)$ was done. We demonstrate that downregulation of $A h H K 1$ drastically reduced nodule formation, underscoring the importance of cytokinin signaling mediated through $A h H K 1$ during nodule initiation in A. hypogaea. The IZ of AhHK1-RNAi nodules contained mitotically active cells associated with high expression of a mitotic cyclin $A h C y c B 2.1$, indicating a prolonged proliferating state during nodule development in A. hypogaea in the absence of cytokinin signaling. These cells in the AhHK1-RNAi nodules contained a distinctly spherical nucleus with significant increase in nucleocytoplasmic index, suggesting that these cells retained some features of the dedifferentiated cells that continued to proliferate and failed to differentiate. Also, the endocytosed rodshaped rhizobia failed to differentiate into bacteroids within spherical symbiosomes, indicating the endosymbionts to be in their undifferentiated state in the AhHK1-RNAi IZ cells. In accordance with the proliferating and undifferentiated state of the AhHK1-RNAi IZ cells, expression of a retinoblastoma-related protein $(A h R B R)$ that restrains proliferation for favoring differentiation of plant cells was lower in AhHK1-RNAi nodules whereas expression of a meristem maintenance factor such as WUSCHEL-RELATED HOMEOBOX5 (AhWOX5) was significantly higher. Our results suggest that $A h H K 1$-mediated cytokinin signaling has a role in both nodule initiation and its subsequent differentiation during nodule development in A. hypogaea.

\section{RESULTS}

\section{Cytokinin signaling is essential for inception} and maturation of nodules in A. hypogaea.

To unravel the role of cytokinin signaling in A. hypogaea RNS, genes encoding the cytokinin receptor $A h H K 1$ (2,928 bp, KT153625) and its paralogues $A h H K 2$ (3,711 bp, KY368747) and $A h H K 3$ (3,102 bp, KY368748) were amplified from nodule cDNA by a degenerate priming approach. The predicted receptor proteins contain two transmembrane domains flanking the extracellular cytokinin perceiving CHASE domain in the $\mathrm{N}$ terminus and the HK domain followed by the receiver domain in the cytoplasmic $\mathrm{C}$ terminus (Supplementary Fig. S1). The steady-state level of $A h H K 1$ transcript was significantly higher than $A h H K 2$ and $A h H K 3$ in uninfected as well as nodulated roots and its level remained almost unchanged during the progress of RNS (Fig. 1A and B). In response to exogenous application of cytokinin, the expression of $A h H K 1$ alone increased rapidly in A. hypogaea roots, whereas that of $A h H K 2$ and $A h H K 3$ decreased significantly (Fig. 1C). In a phylogenetic tree of cytokinin receptors from diverse species, AhHKl clustered within the HK1/4 subgroup along with MtCRE1 and LHK1 (Fig. 1D), the HK that are demonstrated to be the most important for RNS (GonzalezRizzo et al. 2006; Murray et al. 2007). Together, these results suggested that $A h H K 1$ is important for RNS in A. hypogaea. It may be noted that all the three $A h H K(A h H K 1,-2$, and -3) from A. hypogaea are placed at the point of divergence of legumes from nonlegumes (Fig. 1D), which was also observed for $A h S Y M R K$ and $A h C C a M K$ in their respective distance trees (Saha et al. 2014; Sinharoy and DasGupta (2009). Separation between the A. hypogaea genes and the other legume genes correlates with the rhizobial colonization by crack entry in Aeschynomene legumes versus rhizobial colonization through infection thread in other legumes such as Cicer arietinum, Cajanus cajan, M. truncatula, Phaseolus vulgaris, L. japonicus, and Glycine max.

To determine the role of $A h H K 1$-mediated cytokinin signaling in A. hypogaea nodule development, the transcript encoding this receptor was downregulated by introducing an RNAi construct that targets the extracellular CHASE domain. There was approximately $80 \%$ reduction of $A h H K 1$ transcript in $A h H K 1$ $R N A i$ hairy roots without having any significant interference with $A h H K 2$ and $A h H K 3$ expression (Fig. 2A). Nodule development was monitored in vector-transformed and AhHKl-RNAi roots over a period of 5 weeks after infection (WAI) with Bradyrhizobium sp. SEMIA6144 (Fig. 2B). Bump-like protrusions in the lateral root base were noted in the vector-transformed hairy roots within $1 \mathrm{WAI}$ and were identified as nodule primordia. AhHKlRNAi roots at the same period did not show any sign of nodule development. At approximately $3 \mathrm{WAI}, 83 \%$ of the vectortransformed plants $(n=30)$ developed functional nodules, as indicated by their ability to reduce acetylene (Fig. 2C and D). In AhHK1-RNAi roots, we noted bump-like protrusions by 3 to 4 WAI. Concomitant with the emergence of these nodules-like structures by 3 to $4 \mathrm{WAI}$, the composite plants with RNAi roots lost vigor and almost $50 \%$ of the plants died before nodulation was scored at 5 WAI. At approximately $5 \mathrm{WAI}, 37 \%$ of the green fluorescent protein (GFP)-positive roots in the AhHK1-RNAi plants $(n=40)$ developed small white nodules at the lateral root bases (Fig. 2B and C). These nodules developed in $A h H K 1-R N A i$ roots at $5 \mathrm{WAI}$ and were unable to reduce acetylene, indicating that they were nonfunctional (Fig. 2D). In comparison, nodules developed in vector-transformed roots were noted to be functional by 3 WAI. Overall, there was a considerable delay in nodule inception in the AhHK1-RNAi roots, 
with approximately $80 \%$ reduction in nodule number, which could be attributed to approximately $80 \%$ reduction in $A h H K 1$ transcript level. A similar delay in nodulation was also observed in the RNAi lines of MtCRE1 or AeHKl (Fabre et al. 2015; Gonzalez-Rizzo et al. 2006) or in the cytokinin receptor mutants such as crel-1 and lhkl-1 (Murray et al. 2007; Plet et al. 2011). Because the transcript levels of $A h H K 2$ and $A h H K 3$ remained unaltered in the AhHK1-RNAi roots, it is possible that $A h H K 2$ and $A h H K 3$ partially compensated the loss of $A h H K 1$, which enabled the residual nodulation in the AhHK1-RNAi lines (Fig. 2A). Moreover, the residual nodulation can also be attributed to the residual $A h H K 1$ expression in the AhHK1-RNAi lines.

\section{RNAi of $A h H K 1$ affects both cytokinin signaling and the SYM pathway.}

As a readout of cytokinin response, we monitored the level of three type-A RR transcripts in AhHK1-RNAi roots (namely $A h R R 5, A h R R 3$, and AhRR9) whose homologs are involved in the cytokinin response of symbiotic signaling (Fig. 3A). AhRR5 is a homolog of $L j R R 5 / M t R R 8$ that is transcriptionally induced in the presence of rhizobia (Op den Camp et al. 2011; Saur et al. 2011; Tirichine et al. 2007). AhRR3 is a homolog of MtRR4 that functions downstream of MtCRE1 in M. truncatula and is inducible by rhizobia (Gonzalez-Rizzo et al. 2006; Plet et al. 2011). $A h R R 9$ is a homolog of MtRR9 that is transcriptionally induced in the presence of Nod factor (Op den Camp et al. 2011). There was a rapid increase in all three RR transcripts within $3 \mathrm{~h}$ of the application of $10^{-8} \mathrm{M}$ 6-benzylaminopurine (BAP), with the highest expression being that of $A h R R 3$ (approximately sevenfold), indicating their cytokinin responsiveness in A. hypogaea roots (Fig. 3B). Also, transcripts for all three type-A RR were elevated in mature $A$. hypogaea nodules, with the highest expression being that of AhRR5 (approximately 60-fold), suggesting their link with nodule development (Fig. 3C).
To clarify the role of $A h H K 1$ in determining the expression of these type-A RR, we monitored their expression in AhHK1-RNAi uninfected roots as well as in the ineffective nodules that developed at $5 \mathrm{WAI}$ in these roots. As a control, we used the uninfected vector-transformed roots and the effective nodules that developed at $3 \mathrm{WAI}$ in these control roots. The expression of $A h R R 5$ and $A h R R 3$ was significantly lower in both uninfected roots and infected AhHK1-RNAi nodules as compared with their counterparts in vector-transformed roots (Fig. 3C). However, expression of $A h R R 9$ was unaffected in both $A h H K 1-R N A i$ roots and nodules. Results indicate that $A h R R 3$ and $A h R R 5$ were transcriptionally upregulated by $A h H K 1$-mediated cytokinin signaling whereas expression of $A h R R 9$ was apparently not affected by this pathway in A. hypogaea roots.

For the readout of the symbiotic signaling, we chose to monitor the expression of symbiotic genes such as NIN, ENOD40, CYCLOPS, EFD, and SYMREM1, whose homologs are significantly upregulated during progress of symbiosis in Medicago and Lotus spp., though their symbiotic functions remain to be established in A. hypogaea (Crespi et al. 1994; Lefebvre et al. 2010; Marsh et al. 2007; Toth et al. 2012; Vernie et al. 2008; Yano et al. 2008). NIN and ENOD40, the important markers for nodule organogenesis, are reported to be cytokinin induced in Medicago spp. (Gonzalez-Rizzo et al. 2006; Lee et al. 2007; Plet et al. 2011). In $A$. hypogaea roots, there was a rapid increase in transcripts encoding AhNIN and AhENOD40 within 15 to $30 \mathrm{~min}$ of the application of $10^{-8} \mathrm{M}$ BAP, indicating that their cytokinin responsiveness was conserved in A. hypogaea (Fig. 4A). Both AhNIN and AhENOD4O were highly upregulated in wild-type (WT) nodules and, in AhHK1-RNAi nodules, their expression was significantly downregulated (Fig. 4B). This confirms the importance of cytokinin signaling in regulating their expression and suggests a conservation of their symbiotic function in $A$. hypogaea. Symbiotic genes such as CYCLOPS/IPD3, SYMREM1, and
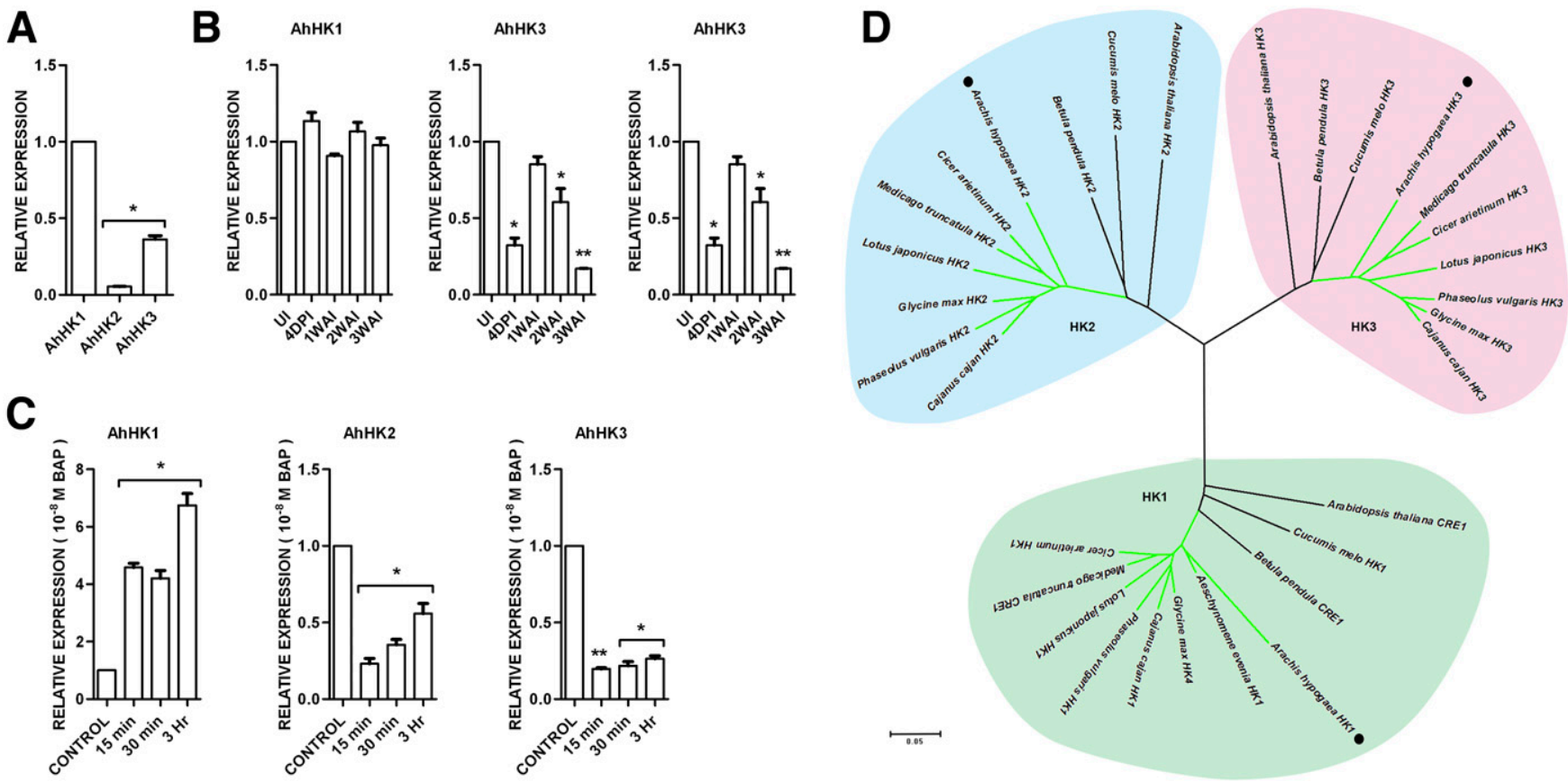

Fig. 1. Expression and phylogeny of cyclase/histidine kinase-associated sensing extracellular domain containing putative cytokinin receptor histidine kinases (HK) in Arachis hypogaea. Quantitative reverse-transcription polymerase chain reaction analysis of $A h H K 1, A h H K 2$, and $A h H K 3$ in $\mathbf{A}$, uninfected roots relative to $A h H K 1$ and $\mathbf{B}$, infected roots at indicated time periods relative to uninfected roots (UI); 4DPI $=$ infected roots at 4 days postinfection, $1 / 2 \mathrm{WAI}=$ nodulated roots at 1 or 2 weeks after infection, and $3 \mathrm{WAI}=$ nodules. C, Roots treated with $10^{-8} \mathrm{M}$ 6-benzylaminopurine (BAP) for indicated time periods relative to untreated roots (Control). AhACTIN was used as reference. Histogram represents an average of three biological replicates, each having $n>3$ plants, and error bar represents standard deviation. Wilcoxon matched-pairs signed rank test was used to assess significant differences, where $* *$ and $*$ indicate $P<0.008$ and 0.05, respectively. D, Neighbor-joining distance tree (Saitou and Nei 1987) of HK using MEGA5 (Tamura et al. 2011) based on CLUSTALW alignment of 960 amino acids. Legumes are indicated by light branches and AhHK are indicated by closed circle. 
$E F D$ play essential roles in bacterial release and differentiation during nodule development in M. truncatula and L. japonicus (Lefebvre et al. 2010; Ovchinnikova et al. 2011; Toth et al. 2012; Vernie et al. 2008; Yano et al. 2008). Expression of $A h C Y C L O P S, A h E F D 1$, and AhSYMREM1 was upregulated during symbiosis in A. hypogaea but, unlike AhNIN and $A h E N O D 40$, their expression was not induced in the presence of $10^{-8} \mathrm{M}$ BAP (Fig. 4A and B). However, in AhHKlRNAi nodules, expression of AhCYCLOPS, AhSYMREM1, and $A h E F D 1$ was significantly downregulated (Fig. 4B). It is possible that cytokinin signaling functions in concert with other signaling pathways in regulating the expression of these factors. Together, results in this section demonstrate the role of AhHKlmediated cytokinin signaling in determining the expression of symbiotic genes and explains the drastic downregulation of nodulation in the $A h H K 1-R N A i$ roots.
Interference of $A h H K 1$-mediated cytokinin signaling impedes the onset of differentiation

in A. hypogaea nodules.

We next wanted to understand the specific stages of nodule development that were affected by the silencing of cytokinin signaling in addition to its requirement for cell proliferation during nodule initiation. For this, we monitored the ultrastructure of the primordia and nodules developed in AhHK1-RNAi roots. As indicated in Figure 2, nodule primordia developed within 1 WAI in vector-transformed roots. The longitudinal sections of these primordia revealed one or more centrally located pockets of rhizobia-infected cells that were surrounded by layers of uninfected cells (Fig. 5A). These rhizobia-containing cells were distinct by having reduced calcofluor-binding ability, indicating that they are thin walled (Fig. 5B and C). Such alteration in the cell wall structure of the rhizobia-containing cells in early stages
A
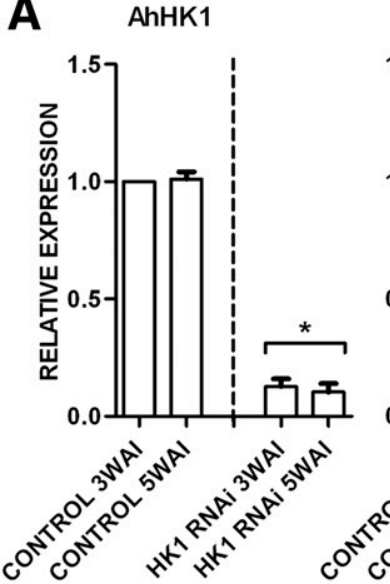

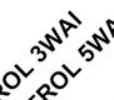

AhHK2
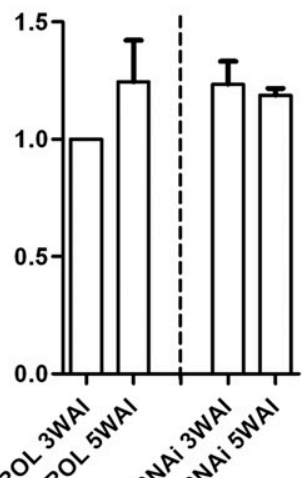
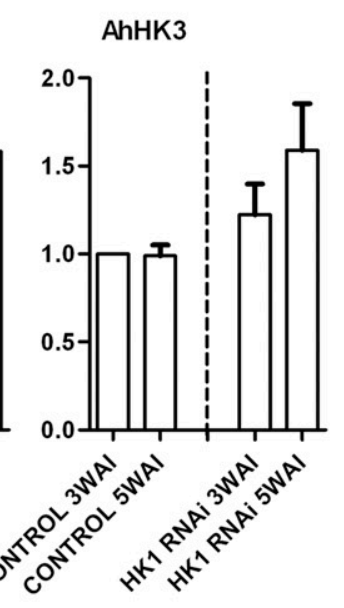

B
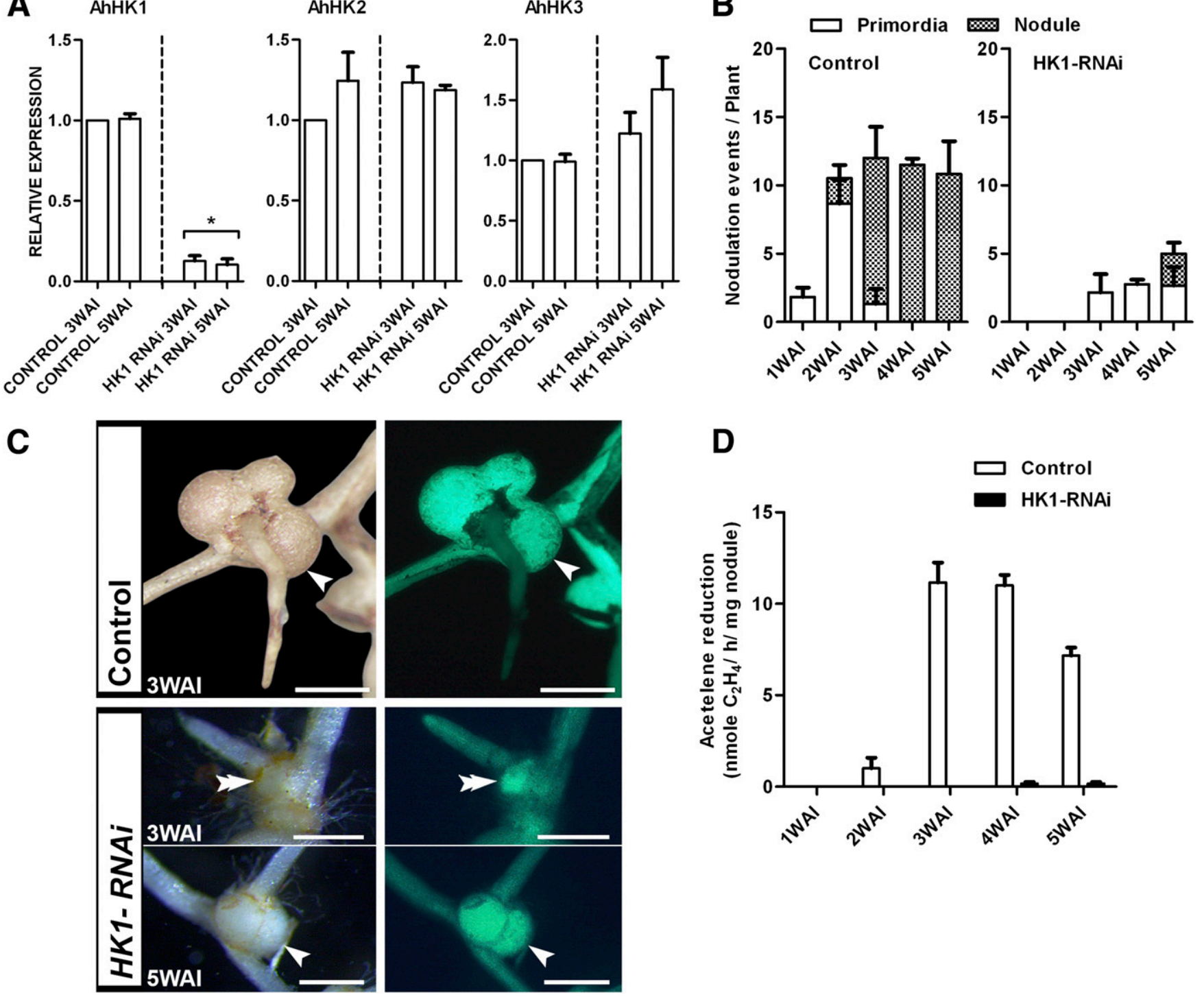

Fig. 2. RNA interference (RNAi) of $A h H K 1$ affects nodulation in Arachis hypogaea. A, Quantitative reverse-transcription polymerase chain reaction analysis of $A h H K 1, A h H K 2$, and $A h H K 3$ in nodules formed in vector-transformed roots (Control) at 3 and 5 weeks after infection (WAI) and AhHK1-RNAi roots at 3 WAI (primordia) and $5 \mathrm{WAI}$ relative to their expression in nodules formed on control roots at $3 \mathrm{WAI}$. AhACTIN was used as a reference gene. Histogram represents an average of three biological replicates, each having $n>4$ root systems, and error bar represents standard deviation. Wilcoxon matched-pairs signed rank test was used to assess significant differences, where * indicates $P<0.05$. B, Nodulation events in AhHK1-RNAi roots as compared with control roots at 1 to 5 WAI Open box indicate primordia and shaded box indicate nodules. Error bar represents standard deviation $(n=30$ for control plants and $n=40$ for $A h H K 1-R N A i$ plants). C, Stereoimages of indicated nodules shown as bright-field and green fluorescent protein. Arrow $=$ nodule and double arrowhead $=$ primordia. Scale bar: $500 \mu \mathrm{m}$. D, Acetylene reduction assay in control and AhHKl-RNAi nodules at indicated WAI. Histogram represents an average of three biological replicates, each having $n>2$ root systems, and error bar represents standard deviation. 
of infection of A. hypogaea was also reported by Chandler et al. (1978). In the primordia, cells within the infection pocket and in the surrounding uninfected zone (SUZ) showed an enlarged nucleus with bigger and denser nucleolus in comparison with root cells (Supplementary Fig. S2). A magnified view revealed the intracellularized rhizobia within the infection pocket to be undifferentiated and rod shaped (Fig. 5D). These infection pockets act as IZ founder cells and it is their uniform division and differentiation that give rise to the distinct aeschynomenoid-type IZ in mature nodules. There has not been a single case where an uninfected primordia was noted $(n=20)$, which is in accordance with the proposition of infection preceding development of aeschynomenoid nodules (Fabre et al. 2015). In AhHK1-RNAi roots, the primordia were noted only 3 WAI (Fig. 5E). Similar to
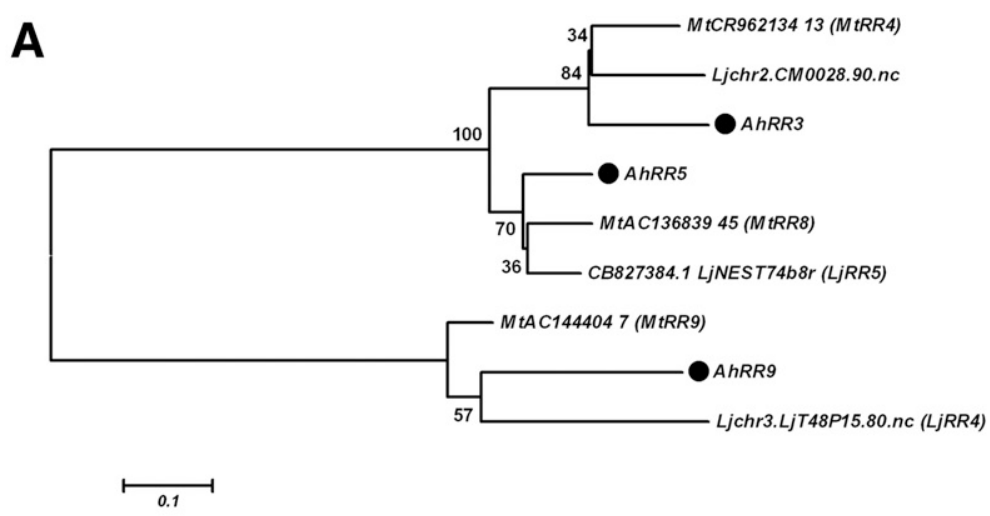

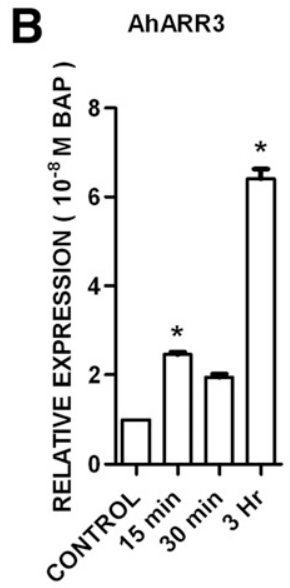

C AhARR3
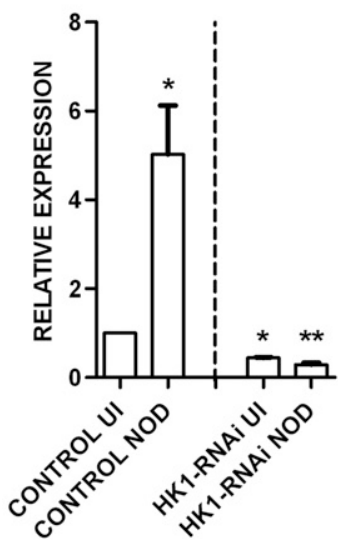

AhARR5

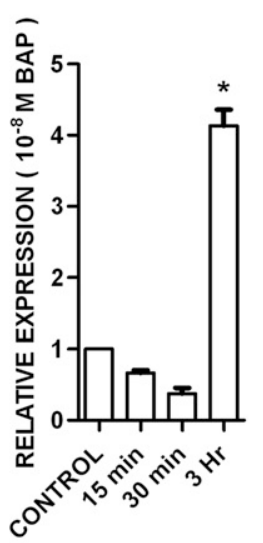

AhARR5

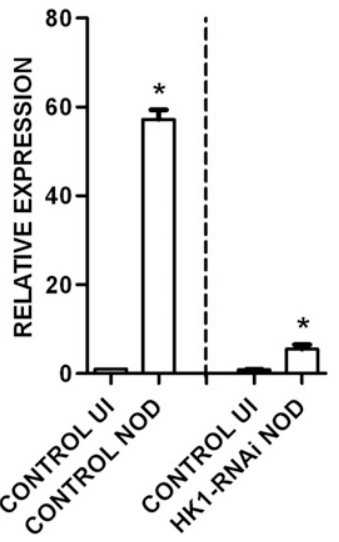

AhARR9

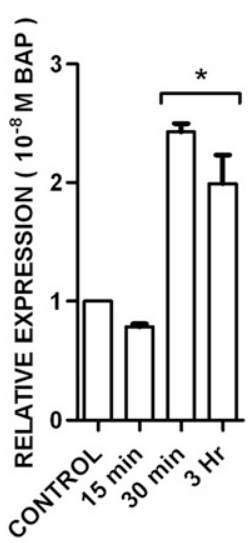

AhARR9

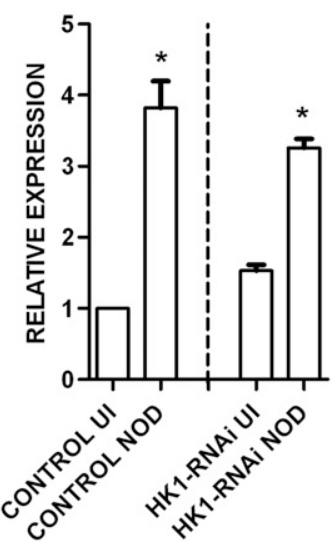

Fig. 3. Phylogeny and expression analysis of AhRR3, AhRR5, and AhRR9. A, Neighbor-joining distance tree (Saitou and Nei 1987) of indicated type-A response regulators (RR) from Arachis hypogaea, Medicago truncatula, and Lotus japonicus was generated using MEGA5 (Tamura et. al. 2011) based on CLUSTALW alignment of 225 nucleotides. AhRR are indicated by a closed circle. Quantitative reverse-transcription polymerase chain reaction analysis of $A h R R 3, A h R R 5$, and $A h R R 9$ in B, roots treated with $10^{-8} \mathrm{M}$ 6-benzylaminopurine (BAP) for the indicated time periods relative to untreated (Control) roots and C, uninfected vector-transformed and $A h H K 1-R N A i$ roots and in nodules developed in vector-transformed ( 3 weeks after infection [WAI]) and AhHK1-RNAi (5 WAI) roots relative to Control uninfected roots (UI). AhACTIN was used as a reference gene. Histogram represents an average of three biological replicates, each having $n>4$ plants, and error bar represents standard deviation. Wilcoxon matched-pairs signed rank test was used to assess significant differences, where ** and * indicate $P<0.008$ and 0.05 , respectively. 
the primordia in vector-transformed roots, AhHK1-RNAi primordia had centrally located, rod-shaped, rhizobia-containing cells surrounded by uninfected cells (Fig. 5E to H). As such, apart from a delay and a reduction in the number which unambiguously indicates a role of $A h H K l$ in nodule initiation and the establishment of nodule primordia, no further differences were apparent in the anatomy of the early primordia stage in the AhHKl-RNAi and control roots.

The ultrastructure of ineffective nodules developed by 5 WAI in AhHK1-RNAi roots was compared with the functional nodules that developed in vector-transformed roots by 3 WAI. The vector-transformed roots developed characteristic aeschynomenoid nodules by $3 \mathrm{WAI}$, with no uninfected cells in the IZ, and the rod-shaped rhizobia differentiated into bacteroids within characteristic spherical symbiosomes (Fig. 5I to K). In the $A h H K 1-R N A i$ nodules, the organization of the aeschynomenoid IZ was unaffected (Fig. 5L) and the IZ/SUZ ratios were similar to those of the WT nodules (Supplementary Fig. S3). The load of the symbionts also appeared to be uniform in all IZ cells of the $A h H K 1-R N A i$ nodules, indicating that proper synchronization of cell division between the host and the symbionts was not perturbed by $A h H K 1$ downregulation (Fig. 5M). However, there were stark differences between the control nodules and the AhHK1-RNAi nodules in the later stages of development, the primary distinctions being (i) the IZ of the AhHKI-RNAi nodules comprised actively dividing cells with mitotic index $>6$, as opposed to the WT mature nodules that were devoid of any dividing cells (Fig. 5I to $\mathrm{K}$ and $\mathrm{L}$ to R; Supplementary Fig. S4; Table 1); and (ii) the IZ cells of the AhHKl-RNAi nodules had a twofold higher density of infected cells as compared with the IZ of the vector-transformed nodules. However, the total number of infected cells in the IZ of AhHKI-RNAi nodules was always higher as compared with a similar-sized WT nodule (Supplementary Table S1). The proliferative state can be explained by a delay in the process of nodule development but a simple delay doesn't explain the increase in the number of total cells in AhHK1-RNAi nodules. Finally, unlike WT nodules where the rhizobia mature into bacteroids within a spherical symbiosome, in the AhHK1-RNAi nodules, rhizobia maintained their native rod form, indicating that cytokinin signaling is also important for the differentiation of the symbionts (Fig. 5L to R). Taken together, these results indicate that cytokinin signaling is important for the proliferation or differentiation of both host cells and the symbionts during the development of aeschynomenoid nodules in A. hypogaea.

\section{Characteristics of the undifferentiated AhHK1-RNAi nodules.}

Apart from being characterized by their smaller size and higher mitotic index, both the IZ and SUZ cells in the AhHKI-RNAi nodules showed a significant increase in nucleo-cytoplasmic index compared with the control vector-transformed nodules (Fig. 6A).
A

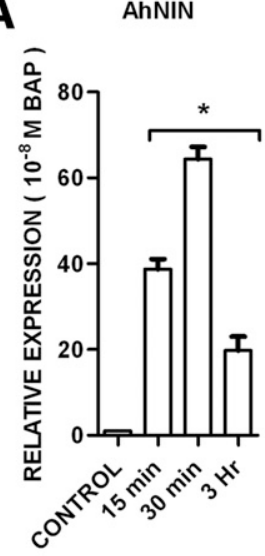

B
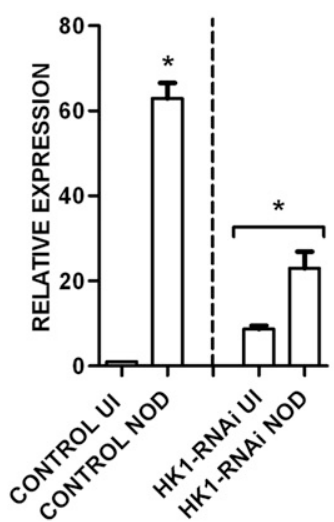

AhENOD40

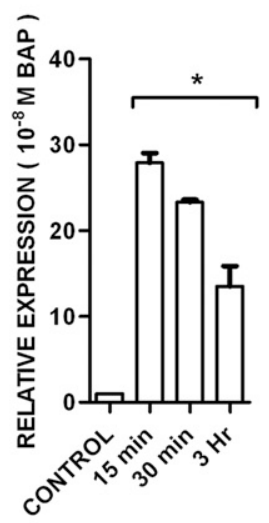

AhENOD40
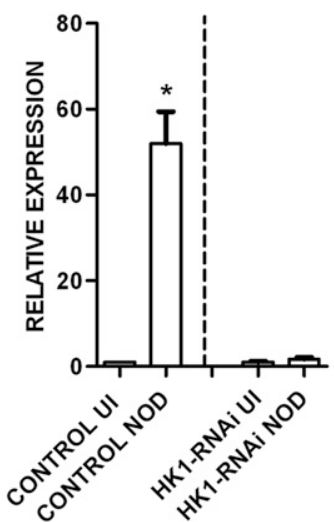

AhCyclops

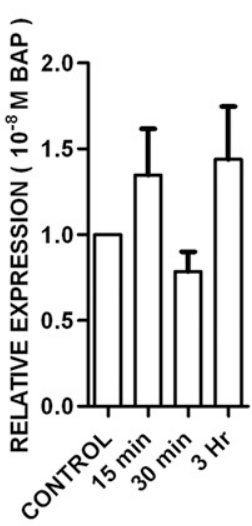

AhCyclops

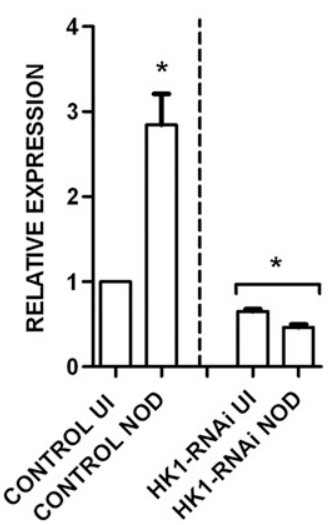

AhEFD1

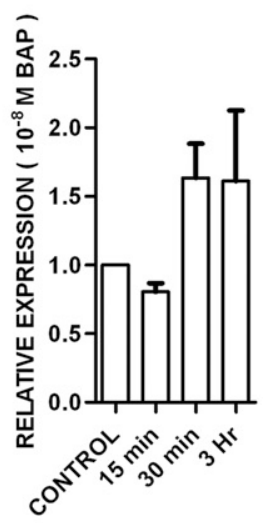

AhEFD1

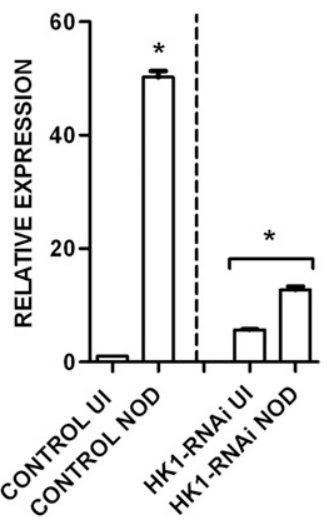

AhSYMREM1

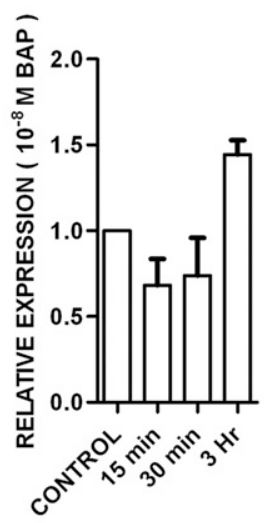

AhSYMREM 1

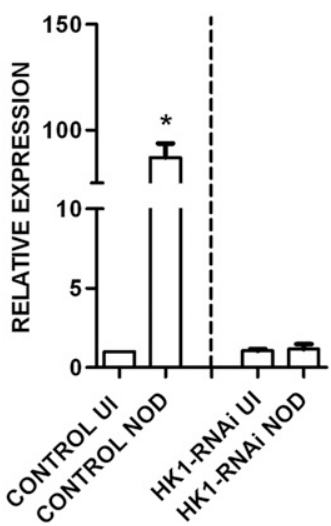

Fig. 4. RNA interference (RNAi) of $A h H K 1$ affects the SYM pathway. Quantitative reverse-transcription polymerase chain reaction analysis of indicated genes in $\mathbf{A}$, roots treated with $10^{-8} \mathrm{M}$ 6-benzylaminopurine (BAP) for the indicated time periods relative to untreated (Control) roots and $\mathbf{B}$, uninfected vectortransformed and $A h H K 1-R N A i$ roots and nodules developed in vector-transformed (3 weeks after infection [WAI]) and AhHK1-RNAi (5 WAI) roots relative to Control uninfected roots (UI) roots. AhACTIN was used as a reference gene. Histogram represents an average of three biological replicates, each having each $n>4$ plants, and error bar represents standard deviation. Wilcoxon matched-pairs signed rank test was used to assess significant differences, where * indicates $P<0.05$. 
Nucleus/cell and nucleolus/cell ratios both were higher in the $A h H K 1-R N A i$ nodules whereas the nucleus/nucleolus ratio was lower (Fig. 6B to D). Additionally, the IZ cells in the AhHK1$R N A i$ nodules had a distinctly spherical nucleus and dense cytoplasm (Fig. 6E and F to H; Supplementary Fig. S5). The IZ cells were occasionally binucleated and sometimes a single nucleus had two nucleoli (Fig. 6G and H). These are some of the characteristic features of pluripotent stem cells in plants (Verdeil et al. 2007) and, therefore, it is possible that the infected cells in the AhHK1-RNAi nodules have retained some features of the dedifferentiated cells that continued to proliferate and failed to differentiate in the absence of cytokinin signaling.

We then used molecular markers to justify the proliferating and undifferentiated state of the IZ cells in AhHK1-RNA $i$
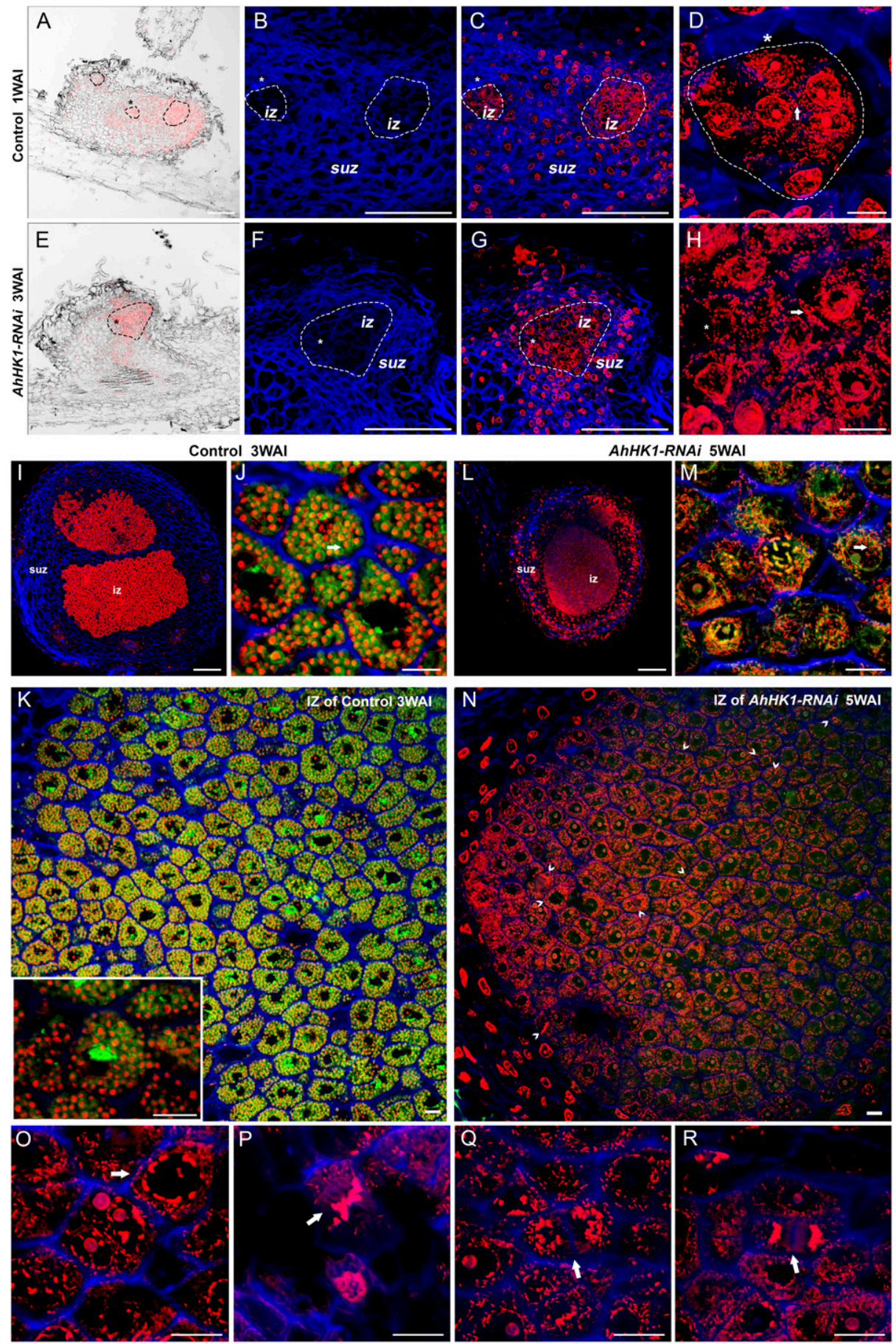

Fig. 5. Ultrastructure analysis of nodules developed in $A h H K 1-R N A i$ roots. Sections of nodule primordia from $\mathbf{A}$ to $\mathbf{D}$, control vector-transformed roots at 1 week after infection [WAI] and $\mathbf{E}$ to $\mathbf{H}, A h H K 1-R N A i$ roots at $3 \mathrm{WAI}(\mathrm{E}-\mathrm{H})$. A and $\mathbf{E}$, Bright field and propidium iodide (PI) merged. B to D and F to H are magnified images of A and E, respectively. B and $\mathbf{F}$, Calcofluor stained; $\mathbf{C}, \mathbf{D}, \mathbf{G}$, and $\mathbf{H}$, calcofluor and PI merged. Dashed line encircles the infection zone (IZ). SUZ = surrounding uninfected zone, arrow $=$ rod-shaped rhizobia, and asterisk indicates identical position in A to D and $\mathrm{E}$ to $\mathrm{H}$. Scale bar: $100 \mu \mathrm{m}(\mathrm{A}$ to $\mathrm{C}$ and $\mathrm{E}$ to $\mathrm{G}$ ) or $10 \mu \mathrm{m}(\mathrm{D}$ and $\mathrm{H})$. Sections of nodules from $\mathbf{I}$ to $\mathbf{K}$, control vector-transformed roots at $3 \mathrm{WAI}$ and $\mathbf{L}$ to $\mathbf{R}$, AhHK1-RNAi roots at $5 \mathrm{WAI}$. J to K and $\mathrm{M}$ to $\mathbf{N}$ are magnified images of IZ shown in I and L, respectively. Inset in K shows magnified IZ cells. Magnified images of IZ cells in $\mathrm{N}$ showing $\mathbf{O}$, early prophase; $\mathbf{P}$, metaphase; $\mathbf{Q}$, anaphase; and $\mathbf{R}$, telophase. Arrows indicate spherical symbiosome (J) and rod-shaped rhizobia (M); wedged arrowhead indicates dividing cells (N). I, L, and $\mathbf{O}$ to R, Calcofluor and PI merged; J, K, M, and N, calcofluor, PI, and Syto9 merged. Scale bar: $100 \mu \mathrm{m}$ (I and L) and $10 \mu \mathrm{m}$ (J, K, and $\mathrm{M}$ to R). Inset scale bar $=10 \mu \mathrm{m}$. 
nodules. As a molecular marker for proliferation, we monitored the level of expression of a type-B cyclin, $A h C y c B 2.1$. It is a homolog of $G m C y c B 2.1$ that has been implicated to have a role in regulating host cell division during nodule organogenesis in G. $\max$ (Mortier et al. 2011). In vector-transformed nodules, there was upregulation of $A h C y c B 2.1$ at 1 WAI, after which its expression drastically decreased in the mature nodules. In AhHK1-RNAi roots, there was a steady increase in the level of expression of $A h C y c B 2.1$ from 2 WAI onward and the expression was approximately threefold more in the $A h H K 1-R N A i$ nodules (Fig. 6I). This high expression of $A h C y c B 2.1$ is in accordance with the proliferating state of the IZ cells in the AhHKI-RNAi nodules. As a marker for the proliferative state of the IZ cells in the $A h H K 1-R N A i$ nodules, we also monitored the level of $A h R B R$, whose downregulation causes overproliferation and delayed differentiation in the root apical meristem (RAM) of Arabidopsis (Borghi et al. 2010). We wanted to check whether the level of $A h R B R$ expression was correlated with the proliferating state of $A h H K 1-R N A i$ nodules. Our results reveal that, in vector-transformed roots, there was a significant increase (20-fold) of $A h R B R$ expression during nodule development by 2 WAI, after which it decreased (Fig. 6J). In AhHK1-RNA $i$ nodules, $A h R B R$ level was maximal at $3 \mathrm{WAI}$, with only fivefold increase in expression. It is possible that the role of RBR in restraining cell division is functionally conserved during nodule development because its downregulation in AhHKl-RNAi nodules correlates with the proliferative and undifferentiated state of the infected host cells.

The homeobox protein WOX5 is a marker for meristem maintenance in RAM of Arabidopsis thaliana and MtWOX5 is found to be expressed within nodule meristems in M. truncatula (Franssen et al. 2015; Osipova et al. 2012; Sarkar et al. 2007). Therefore, we chose to monitor the expression of AhWOX5 with the progress of symbiosis in AhHKl-RNAi roots. In vector-transformed roots, $A h W O X 5$ expression was approximately 50 -fold higher in developing nodules at $2 \mathrm{WAI}$ as compared with the uninfected roots. The level of AhWOX5 almost reduced to its basal level in the mature nodules at 3 WAI (Fig. 6K). This transient expression pattern of $A h W O X 5$ was similar to what was observed for MtWOX5 in M. truncatula and PsWOX5 in Pisum sativum (Osipova et al. 2012). In $A h H K 1-R N A i$ roots, the AhWOX5 level gradually increased up to 85 -fold by 5 WAI in the ineffective nodules as opposed to only 7-fold higher expression in the effective and mature nodules that developed in the vector-transformed roots by 3 WAI (Fig. 6K). Thus, unlike the differentiation-promoting factors such as $A h R B R$, whose expression decreased, the expression of a meristem maintenance factor such as AhWOX5 increased in AhHKl-RNAi nodules. In situ hybridization was done to determine the spatial pattern of $A h W O X 5$ expression during nodule development (Fig. 6L to O). In the vector-transformed roots at $1 \mathrm{WAI}, A h W O X 5$ transcript was detected primarily in the IZ of the nodule primordia, with weak expression in the vascular bundles (Fig. 6L). In the mature nodules at $3 \mathrm{WAI}, A h W O X 5$ was absent from the IZ but was detected in the vascular bundles (Fig. 6M). In the AhHK1-RNAi nodule primordia at $3 \mathrm{WAI}, A h W O X 5$ expression was restricted to the IZ and vascular bundles, which is similar to what was observed in the control nodule primordia (Fig. $6 \mathrm{~N}$ ). However, in the AhHK1-RNAi nodules at 5 WAI, AhWOX 5 expression was still detectable in both the IZ and the vascular bundles (Fig. 6O). These results demonstrate that both the level and the site of AhWOX5 expression changes in the AhHK1-RNAi nodules. Because the WUSCHEL HOMEOBOX (WOX) TF are central regulators of stem cell specification in diverse meristems, the elevated level of AhWOX5 transcript in the $A h H K 1-R N A i$ nodules is in accordance with the undifferentiated state of infected host cells in the absence of $A h H K 1$-mediated cytokinin signaling.

\section{DISCUSSION}

In A. hypogaea, rhizobia are directly endocytosed in cortical cells to generate the founder cells that divide repeatedly to develop the typical aeschynomenoid nodule (Fig. 5). AhHK1-RNAi resulted in a decrease of nodule numbers, indicating that cytokinin signaling mediated through this receptor is important for inception of nodule primordia in A. hypogaea (Figs. 2, 3, 4, and 5). In the later stages, $A h H K 1-R N A i$ IZ cells were noted to be in a proliferative state, suggesting that $A h H K 1$ has a role in differentiation of these cells for the development of mature and effective nodules (Figs. 5 and 6). The endocytosed rhizobia in the AhHK1-RNAi nodules remained in their native rod-shaped form without being differentiated into bacteroids within the spherical symbiosomes (Fig. 5), which is directly linked to nitrogen-fixing efficiency (Oono and Denison 2010). This explains the lack of nitrogen-fixing capability of $A h H K 1-R N A i$ nodules and indicates that $A h H K 1$ signaling is important for the differentiation of both host and symbionts during the development of aeschynomenoid nodules (Figs. 2D and 5). It may be noted that, in both Medicago and Lotus spp., the redundancy of cytokinin signaling mediated through $M t H K 2 / \mathrm{LHK} 2$ and $M t H K 3 / \mathrm{LHK} 3$ led to formation of proper nitrogen-fixing nodules after a considerable delay (Boivin et al. 2016; Held et al. 2014). It is possible that the observed undifferentiated state of host and the symbionts in AhHK1-RNAi nodules was due to a lag in the onset of differentiation and functional nodules could develop after such considerable delay. However, a simple delay does not explain why there would be an increase in infected cell number in the IZ of AhHK1-RNA $i$ nodules. Therefore, it is also possible that the presence of proliferating IZ cells in AhHK1-RNAi nodules is due to lack of a specific signal for differentiation in the absence of $A h H K 1$-mediated cytokinin signaling.

Earlier reports have indicated that the expression of SYM pathway effectors and type-A RR decrease in MtCRE1-RNAi and cre 1/hitl mutants (Gonzalez-Rizzo et al. 2006; Murray et al. 2007; Plet et al. 2011). Similarly, under AhHK1-RNAi conditions, we find drastic downregulation of expression of type-A RR such as $A h R R 3$ and $A h R R 5$, whose homologs were previously been reported to play a significant role during nodulation downstream of cytokinin signaling (Murray et al.

Table 1. Mitotic index (MI) of infection zone in AhHK1-RNAi nodules ${ }^{\mathrm{a}}$

\begin{tabular}{lccccccc}
\hline Set & Number of cells & Interphase & Prophase & Metaphase & Anaphase & Telophase & MI \pm SD $(\%)^{\mathbf{b}}$ \\
\hline 1 & 219 & 204 & 11 & 3 & 1 & 0 & $7 \pm 1.67$ \\
2 & 234 & 222 & 8 & 2 & 1 & $5 \pm 1.15$ \\
3 & 186 & 170 & 10 & 3 & 1 & 1 & $9 \pm 0.41$ \\
4 & 230 & 216 & 9 & 1 & 0 & 0 & 1 \\
5 & 212 & 201 & 9 & 3 & $5 \pm 2.46$ \\
\hline
\end{tabular}

${ }^{a}$ Nodules were harvested from AhHK1-RNAi roots 5 weeks after infection. Three different areas ( 272 by $272 \mu \mathrm{m}$ each) in a nodule section were analyzed for dividing cells. Each row represents observations from a single nodule.

${ }^{\mathrm{b}} \mathrm{MI}$ is calculated using the formula $\mathrm{MI}=[(\mathrm{P}+\mathrm{M}+\mathrm{A}+\mathrm{T}) / \mathrm{N}] \times 100 \% / \mathrm{N}$, where $\mathrm{P}=$ prophase, $\mathrm{M}=$ metaphase, $\mathrm{A}=$ anaphase, $\mathrm{T}=$ telophase, and $\mathrm{N}=$ total number of cells. $\mathrm{SD}=$ standard deviation. 
2007; Op den Camp et al. 2011; Saur et al. 2011). In addition, several SYM pathway effectors were significantly downregulated upon silencing of AhHKl in A. hypogaea (Figs. 3 and 4). $N I N$ and ENOD4O are cytokinin-inducible effectors of the SYM pathway, where MtNIN is required to initiate nodule formation in the cortex and MtENOD4O is a long noncoding RNA that is essential for nodule organogenesis (Crespi et al. 1994; Lee et al. 2007; Marsh et al. 2007). Although both these factors are yet to be characterized in A. hypogaea, inducibility of $A h N I N$ and AhENOD4O by cytokinin and their high expression in A. hypogaea nodules suggests their conserved role in nodule development (Fig. 4). Finally, the significant downregulation of their expression in AhHK1-RNAi nodules confirms their cytokinin responsiveness during A. hypogaea nodule development. CYCLOPS transactivates NIN and functions downstream of CCaMK in the SYM pathway, and SYMREM1 is a symbiotic remorin that interacts with an upstream receptorlike kinase responsible for bacterial recognition (Singh et al. 2014; Toth et al. 2012). Both CYCLOPS and SYMREM1 are essential for bacterial release from infection threads in M. truncatula and L. japonicus but their role in aeschynomenoid nodule development is unknown (Lefebvre et al. 2010; Ovchinnikova et al. 2011; Toth et al. 2012; Yano et al. 2008). Silencing of $A h H K 1$ led to decreased expression of AhCYCLOPS and AhSYMREM1, which possibly explains the drastic downregulation of nodulation because nodule organogenesis is preceded by bacterial endocytosis in A. hypogaea (Boogerd and Rossum 1997). EFD is an ethylene-dependent TF required for nodule differentiation in $M$. truncatula (Vernie et al. 2008). Considering the role of EFD in nodule differentiation, the immature and undifferentiated state of the AhHK1-RNAi nodules might be attributed to a low level of AhEFDl (Fig. 4). Because AhCYCLOPS, AhSYMREM1, and $A h E F D 1$ were not induced by exogenous application of cytokinin, their low expression in $A h H K 1-R N A i$ roots indicates that cytokinin signaling might be necessary in concert with other pathways for regulating their expression. It may be noted that $M t E F D$ negatively affects nodule number $\sin M$. truncatula by inducing type-A RR (MtRR4) (Vernie et al. 2008). This causes feedback inhibition of MtCRE1 and thereby explains why the Mtefd1 mutant shows higher nodulation. In uninfected $A h H K 1$ $R N A i$ roots, there was a significant upregulation of AhEFDl expression, which is in accordance with our present understanding about the negative role of EFD on nodule number. However, elevated expression of $A h E F D 1$ does not explain the reduced expression of AhRR3 and AhRR5 in AhHK1-RNAi roots and, in turn, low expression of type-A RR does not explain the low nodule number under the same conditions (Figs. 3C and 4). This paradox was noted earlier, when RNAi of typeA RR led to a reduction in nodule numbers, which should have increased as per our present understanding on cytokinin signaling (Op den Camp et al. 2011).

The importance of MtCRE1/LHK1 in the inception of nodulation has been widely demonstrated in model legumes such as Medicago spp. (Gonzalez-Rizzo et al. 2006; Plet et al. 2011) or Lotus spp. (Murray et al. 2007). It may be noted that the additional role of $H K 1$ in regulating the transition between meristematic and cell differentiation during RNS was first noted in the Medicago crel mutants (Plet et al. 2011). However, RNAi of MtCRE1 did not reveal any such sign of incomplete differentiation and, like L. japonicus hit1 mutants, could only demonstrate the role of this $\mathrm{HK}$ in the early stages of inception (Gonzalez-Rizzo et al. 2006; Murray et al. 2007; Plet et al. 2011). In A. hypogaea, the IZ in AhHK1-RNAi nodules were densely packed with infected cells with distinctively high mitotic index (Table 1). This was in accordance with significantly high expression of a mitotic cyclin $A h C y c B 2.1$ in $A h H K 1$ $R N A i$ nodules (Fig. 6I). This is similar to the observations in
Arabidopsis RAM, where an inhibitory role of cytokinin is demonstrated to control the number of cell divisions that occur prior to differentiation (Takatsuka and Umeda 2014). Also, reductions in expression of the cytokinin receptor in Arabidopsis cause higher numbers of dividing cells in RAM (Dello Ioio et al. 2008). Cytokinin signaling is also known to activate retinoblastomarelated proteins that restrain the cell cycle in RAM of Arabidopsis for promoting differentiation (Perilli et al. 2013) but its role in nodule meristem is unknown. The proliferative state in the AhHKl$R N A i$ nodules that was associated with low expression of $A h R B R$ suggests that the function of RBR proteins in restraining cell division could be conserved during nodule development, or low expression of $A h R B R$ could also be a consequence of the aberrant morphology of the RNAi nodules (Fig. 6J).

Ultrastructure analysis of AhHK1-RNA $i$ nodules revealed the IZ cells to have some characteristic features of pluripotent stem cells such as high nucleocytoplasmic ratio, spherical nucleus, and multiple nucleoli (Verdeil et al. 2007). Additionally, we noted binucleated IZ cells in the AhHKI-RNAi nodules, which was previously reported for A. hypogaea in AhCCamK-RNAi nodules and for $P$. sativum in the early primordia stage (Sinharoy and DasGupta 2009; Torrey and Barrios 1969). Therefore, it is possible that these cells have retained some features of the dedifferentiated cells that continued to proliferate due to either a delay in the process of nodule development or a lack of signal for differentiation. The observed undifferentiated state of AhHK1-RNAi nodules could be correlated with AhWOX5, because its expression was significantly higher in the ineffective AhHK1-RNAi nodules as compared with the nodules developed in vector-transformed roots that were fully mature and effective (Fig. 6K). WOX TF are central regulators of stem cell maintenance in different meristem types and are also expressed in nodule meristems of M. truncatula (Franssen et al. 2015). In Arabidopsis RAM, AtWOX5 expression decreases with the onset of differentiation and, conversely, its ectopic expression induces a stem-celllike program in differentiated cells (Sarkar et al. 2007). It may be noted that, in RAM, cytokinin is known to negatively regulate AtWOX5 expression (Zhang et al. 2013). Because higher expression of AhWOX5 is associated with silencing of cytokinin signaling in AhHK1-RNAi nodules, cytokinin-regulated repression of AhWOX5 might be conserved in nodule meristems.

Overall, our observations indicate that AhHKl-mediated cytokinin signaling is essential for both inception of nodules and their transition from proliferating to a differentiated cell fate during aeschynomenoid nodule development. Interference of $A h H K 1$ was associated with lower expression of factors such as $A h R B R$ that restrain proliferation to promote differentiation of plant cells (Perilli et al. 2013). Under the same conditions, expression of $A h W O X 5$ was significantly elevated, which is consistent with the undifferentiated state of $A h H K 1-R N A i$ nodules. A role of cytokinin in nodule differentiation was first hinted at in M. truncatula (Plet et al. 2011) but whether factors such as RBR and WOX5 are functionally conserved in root nodule meristems is a subject for future investigation.

\section{MATERIALS AND METHODS}

\section{Plant and rhizobial strains.}

A. hypogaea JL24 strain seed is from ICRISAT, India; Agrobacterium rhizogenes R1000 from C. Somerville, Stanford University; binary vector pK7GWIWG2D(II) from Ghent University, Belgium; and Bradyrhizobium sp. SEMIA6144 from Adriana Fabra, Universidad Nacional de Rio Cuarto, Cordoba, Argentina.

Cloning of A. hypogaea AhHK1, AhHK2, and AhHK3.

$A$. hypogaea $\mathrm{HK}$ were amplified from cDNA prepared from nodulated roots of $A$. hypogaea and cloned following 
standard procedures (Sinharoy and DasGupta 2009). AhHK1 was isolated by amplification of nodule cDNA using a degenerate priming approach based on legume $H K 1$ sequences. Primers 5'ATGGBTYTKGGGTTSARGATG3' and 5'CAA CVKCRTKRTANAGATTYTSTTC 3' were used. Similarly, $A h H K 2$ and $A h H K 3$ were amplified using primers 5'ATGTY TGTSAATAAWAGNAWTTCAGG3' and 5'-CSCTTCBTCAA GCNTAGTTCATAG-3' for AhHK2 and 5'ATGSGTTTGWTC CATNTTGNTGGG-3' and 5'CGGSTTWTCCSABCWTCNT GA-3' for $A h H K 3$.
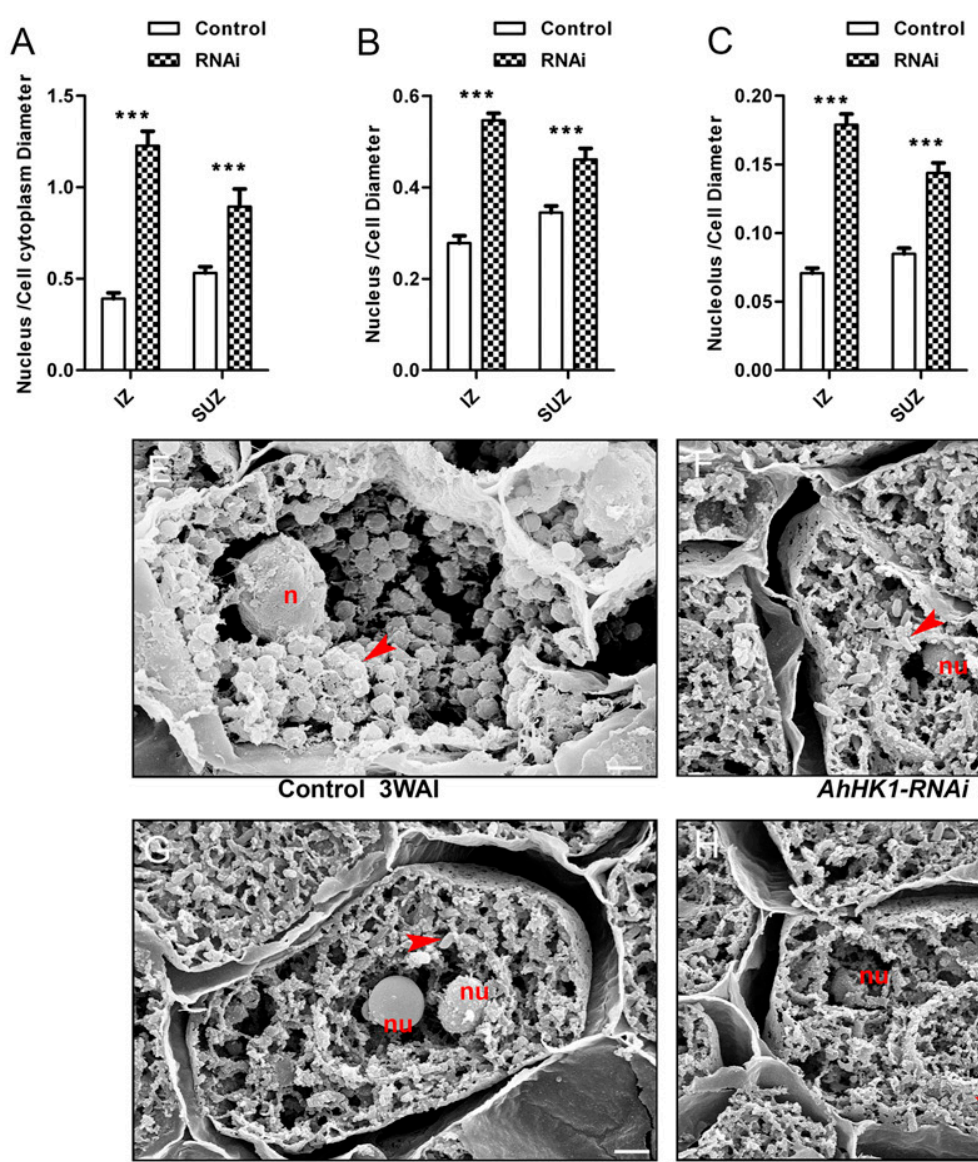

$$
\text { D } \square \text { Contro }
$$
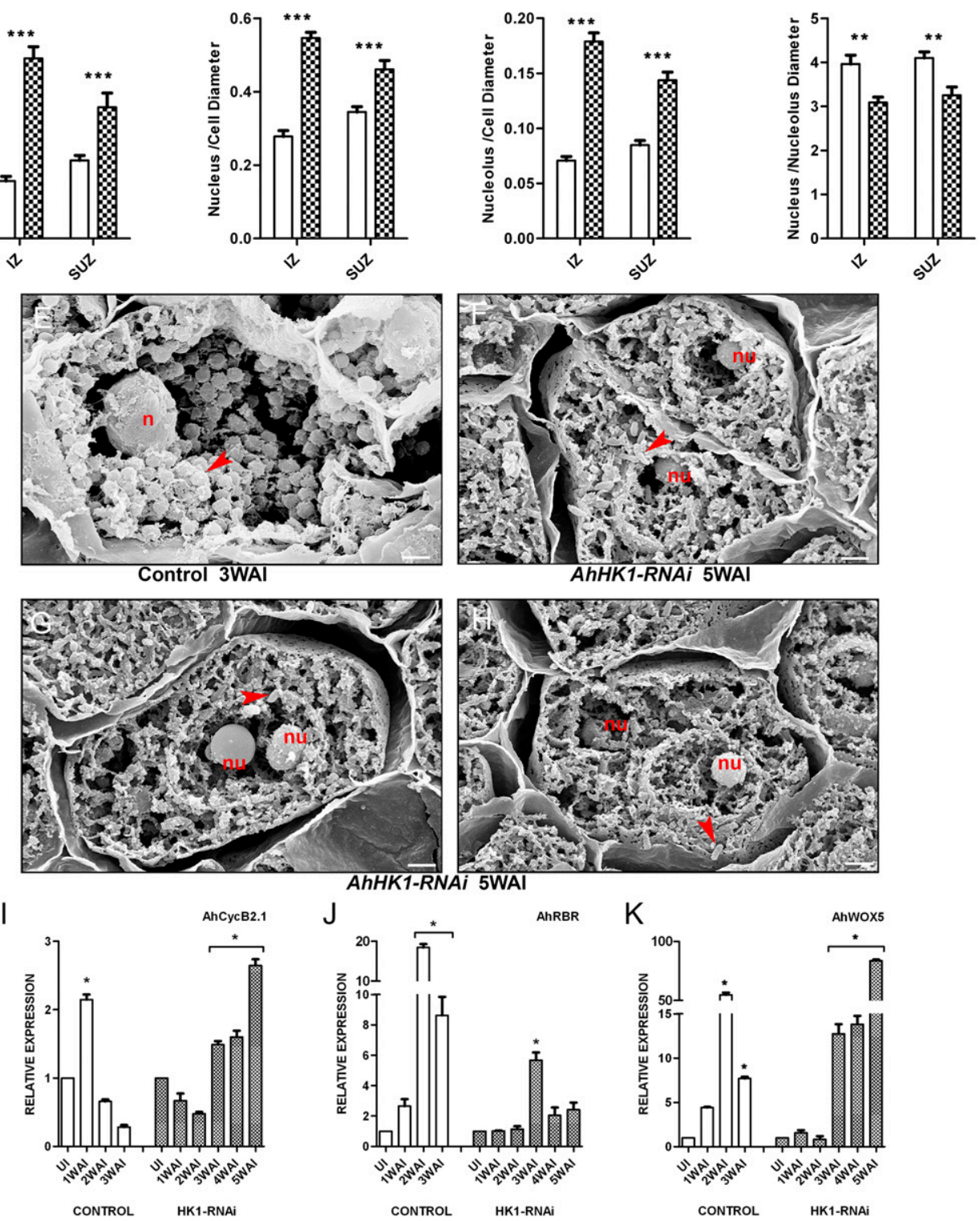

$\mathrm{J}$

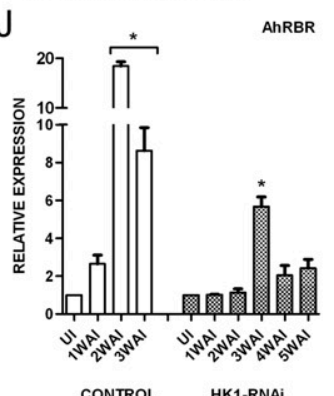

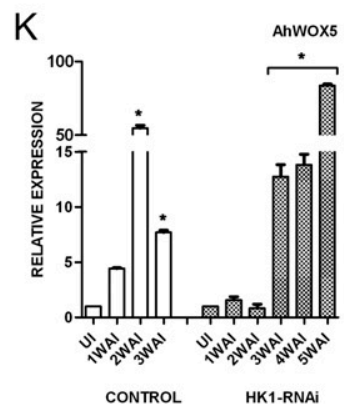
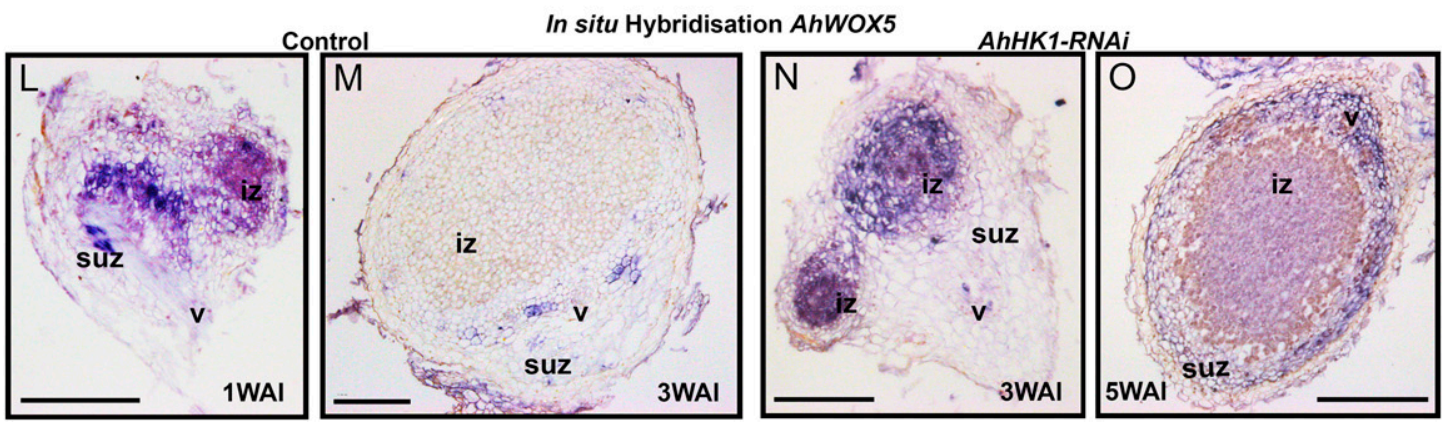

196 / Molecular Plant-Microbe Interactions 


\section{Constructs.}

The AhHK1-RNAi construct was generated by amplification from $A h H K 1$ cDNA template with primers 5'-CACCAACCA TGTCCATGCCCTTGCC-3' and 5'-GCAAGTTGACCAAGTAA ATTCTCCAC-3' complementary to CHASE domain, 522 bp in length. Amplified fragments were cloned into pENTR/D-TOPO (Life Technologies) and then into binary vectors pK7GWIWG2D (II) (Karimi et al. 2002) by gateway technology through the LR Clonase reaction kit (Life Technologies). Constructs are then transformed in Agrobacterium rhizogenes strain R1000 for further experiments.

\section{Transformation with A. rhizogenes and nodulation of transgenic hairy roots.}

Transformation was done according to (Sinharoy et al. 2009). Transformed and untransformed roots in the composite transgenics were differentiated from each other by the expression of the visible marker enhanced GFP by a Leica M205FA stereofluorescence microscope equipped with a Leica DFC310FX digital camera (Leica Microsystems) and are referred to in the article as GFP positive. The selected composite transgenic plants were transplanted either in agar plates containing half-strength Murashige and Skoog (1/2 MS; Hi-media) or vermiculite pots and the plants were maintained in a growth chamber at $26^{\circ} \mathrm{C}$ on a schedule of $16 \mathrm{~h}$ of light and 8 -h of darkness under $60 \mathrm{mmol} / \mathrm{m}^{2} / \mathrm{s}$. Nodulation was scored 1, 2, 3, 4, and 5 WAI for RNAi and control plants. Nitrogen fixation of control and RNAi-transformed roots bearing a similar number of nodules was assayed using nitrogenase acetylene reduction Sinharoy and DasGupta (2009).

\section{Phenotypic analysis and confocal microscopy.}

Images of whole-mount nodulated roots were captured using a Leica M205FA stereofluorescence microscope equipped with a Leica DFC310FX digital camera (Leica Microsystems). Detached nodules were embedded in Shandon cryomatrix (Thermo Scientific) and sliced into 30- $\mu$ m-thick sections with a CM1850 rotary cryomicrotome (Leica Microsystems). For confocal microscopy, sample preparation was done according to Haynes and associates (2004) and Sinharoy and DasGupta (2009). Sections were stained with Calcofluor (Life Technologies), propidium iodide (Life Technologies) and Syto9 (Life Technologies). Images were acquired with a Leica TCS SP5 II AOBS confocal laser-scanning microscope (Leica Microsystems). All digital micrographs were processed using Adobe Photoshop CS5.

\section{Scanning electron microscopy.}

Scanning electron microscopy (SEM) was performed as described by Sinharoy and associates (2009), with some modifications. Whole nodulated roots harvested $3 \mathrm{WAI}$ (control) or 5 WAI (RNAi) were vacuum infiltrated with $2.5 \%$ (vol/vol) glutaraldehyde (Sigma-Aldrich) in 0.1 M PIPES (pH 7.2) buffer
(Sigma-Aldrich) and incubated for $1 \mathrm{~h}$ at room temperature. They were rinsed twice (30 min each) in 0.1 M PIPES ( $\mathrm{pH}$ 7.2). The harvested nodules were dehydrated through a series of ethanol gradients $(20,40,60,75,80,90$, and $100 \%)$ for $1 \mathrm{~h}$ each at room temperature. Nodules were then transferred to $100 \%$ chloroform through a gradient of ethanol/chloroform (3:1, 1:1, and 1:3 [vol/vol]) mixtures. Paraplast (Sigma-Aldrich) was dissolved in chloroform (Sigma-Aldrich) for embedding the tissue and then incubated at 37 and $60^{\circ} \mathrm{C}$ for $2 \mathrm{~h}$ each. Sections $(20 \mu \mathrm{m})$ were prepared using rotary microtome RM2235 (Leica Microsystems) and placed on poly-L-lysine-coated slides (Sigma-Aldrich). Paraplast was removed with xylene. SEM was done using a Zeiss EVO 18 Special Edition (Carl Zeiss).

\section{RNA extraction, cDNA synthesis, and quantitative reverse-transcription polymerase chain reaction.}

Frozen root samples and detached nodules and primordia were ground in liquid nitrogen and total RNA extraction was performed with a NucleoSpin RNA (Macherey-Nagel) plant kit. RNA quality and quantity were analyzed with a NanoDrop spectrophotometer (Thermo Scientific). Total RNA (500 ng) was reverse-transcribed by using Super-ScriptIII RT (Life Technologies) and oligo (dT) ${ }_{17}$. RNA quantity from each sample in each biological replicate was standardized prior to first-strand cDNA synthesis. Quantitative reverse-transcription polymerase chain reaction (PCR) was performed by using Power SYBR Green PCR Master Mix (Applied Biosystems), with primers designed using Oligoanalyser software (Integrated DNA Technology) (Supplementary Table S3). Calculations were done using the $\Delta \Delta$ cycle threshold method, with AhActin as the endogenous control, whose constitutive expression was verified against another housekeeping gene AhUbiquitin (AhUBI2) (Supplementary Fig. S6). The reactions were run in the Applied Biosystems 7500 Fast HT platform as follows: 1 cycle at $50^{\circ} \mathrm{C}$ for $2 \mathrm{~min} ; 1$ cycle at $95^{\circ} \mathrm{C}$ for $5 \mathrm{~min} ;, 40$ cycles at $95^{\circ} \mathrm{C}$ for $30 \mathrm{~s}, 54^{\circ} \mathrm{C}$ for $30 \mathrm{~s}$, and $72^{\circ} \mathrm{C}$ for $30 \mathrm{~s}$; followed by melt curve analysis at 1 cycle at $95^{\circ} \mathrm{C}$ for $1 \mathrm{~min}, 55^{\circ} \mathrm{C}$ for $30 \mathrm{~s}$, and $95^{\circ} \mathrm{C}$ for $30 \mathrm{~s}$ A negative control without cDNA template was checked for each primer combination. Nucleotide sequence data for the genes used in this article can be found in the GenBank data library under the following accession numbers: AhARR3 (KT820784), AhARR5 (KT820785), AhARR9 (KT820786), AhNIN (KT820787), AhWOX5 (KT820790), AhENOD40 (KY401676), AhCYCLOPS (JQ839282.1), AhREMORIN (SYMREM1) (KT988038), AhEFD1 (KT962993), AhHK1 (KT153625), AhActin (EU982407), AhHK2 (KY368747), AhHK3 (KY368748), AhRBR (KT820789), $A h C y c B 2.1$ (MF784810), and AhUBI2(MF784809).

\section{Cytokinin treatments.}

Ten embryonic axes were grown on $1 / 2 \mathrm{MS}$ (Hi-media) plates for 10 days at $26^{\circ} \mathrm{C}$ on a schedule of $16 \mathrm{~h}$ of light and 8 -h of darkness at $60 \mathrm{mmol} / \mathrm{m}^{2} / \mathrm{s}$. After 10 days, rooted embryonic axes were treated with $10^{-8} \mathrm{M}$ BAP (Sigma-Aldrich) for various

\footnotetext{
Fig. 6. Characteristics of the undifferentiated $A h H K 1-R N A i$ nodules. Analysis of nodules collected from control vector-transformed roots at 3 weeks after infection [WAI] and AhHK1-RNAi roots at 5 WAI. Ratio of diameters of A, nucleus/cytoplasm; B, nucleus/cell; C, nucleolus/cell; and D, nucleus/nucleolus. Data scored from 200 infection zone (IZ) cells and 50 surrounding uninfected zone (SUZ) cells from 15 nodules. Error bars represent mean \pm standard error of the mean. A two-way analysis of variance followed by Bonferroni posttests were used to assess significant differences, where $* * *$ and $* *$ indicate $P<0.001$ and 0.01, respectively. Scanning electron microscopy image of an infected cell from the IZ of E, control and F to H, AhHK1-RNAi nodules Arrow indicates spherical symbiosome $(\mathrm{E})$ or rod-shaped rhizobia $(\mathrm{F}$ to $\mathrm{H}) ; \mathrm{n}=$ nucleus and $\mathrm{nu}=$ nucleolus. Scale bar $=2 \mu \mathrm{m}(\mathrm{E}$ to $\mathrm{H})$. Quantitative reverse-transcription polymerase chain reaction analysis of $\mathbf{I}, A h C y c B 2.1 ; \mathbf{J}, A h R B R$; and $\mathbf{K}, A h W O X 5$ with progress of nodulation in control vector-transformed roots ( 1 to $3 \mathrm{WAI})$ and $A h H K 1-R N A i$ roots ( 1 to $5 \mathrm{WAI}$ ). For control roots, UI = uninfected roots; 1 to $2 \mathrm{WAI}=$ nodulated roots, and $3 \mathrm{WAI}=\mathrm{Control}$ nodules. For $A h H K 1-R N A i$ roots, $\mathrm{UI}=$ uninfected roots, 1 to $2 \mathrm{WAI}=$ infected roots, 3 to $4 \mathrm{WAI}=$ primordia containing roots, and $5 \mathrm{WAI}=\mathrm{RNA}$ interference $(\mathrm{RNAi})$ nodules. $A$ hACTIN was used as a reference gene. Histogram represents an average of three biological replicates, each having $n>4$ plants, and error bar represents standard deviation. Wilcoxon matched-pairs signed rank test was used to assess significant differences, where $*$ indicates $P<0.05$. AhWOX5 was localized by in situ hybridization using antisense probes in indicated tissue sections. Nodule primordia: L, control at 1 WAI and N, AhHK-RNA $i$ at 3 WAI. Nodules: M, control at 3 WAI and $\mathbf{O}, A h H K$-RNAi at 5 WAI. Signal corresponds to precipitate marking the activity of the alkaline phosphatase detection system; $\mathrm{v}=\mathrm{vascular}$ bundle, $\mathrm{iz}=$ infection zone, and suz $=$ surrounding uninfected zone. Scale bar $=250 \mu \mathrm{m}$ (L to O).
} 
incubation times and maintained under the same growth conditions. Roots were collected at the indicated time points and immediately frozen in liquid nitrogen for RNA extraction.

\section{In situ hybridization.}

The in situ hybridization probe for AhWOX 5 was created by first amplifying 648-bp fragments by PCR from a template cDNA prepared from total RNA from inoculated roots. The primer set $5^{\prime}$ ATGCAGACGGTCCGAGATCTGTC-3' and 5'-TTACATGAAA CTTAAGCGAAGG-3' was used for the amplification. The fragments were inserted into the pGEM-T easy vector by TA cloning (Promega Corp.). Digoxigenin (DIG)-labeled probes were generated with the SP6/T7 DIG-RNA labeling kit (Roche). Probe synthesis, preparation of sections, and in situ hybridization were performed as described previously (Javelle et al. 2011). In situ hybridization signals were analyzed by light microscopy using a Leica M205FA stereofluorescence microscope equipped with a Leica DFC310FX digital camera (Leica Microsystems).

\section{ACKNOWLEDGMENTS}

This work was funded by grants DBT-CEIB (Centre of Excellence and Innovation in Biotechnology, BT/01/CEIB/09/VI/10) DBT-IPLS (BT/PR14552/INF/22/123/2010), and CEFIPRA (IFC/5103-4/2014/543) from the government of India; and a fellowship to A. Kundu (Council of Scientific and Industrial Research, CSIR-09/028[0756]/2009-EMR-I). We thank T. Das and S. Ghosh for technical assistance and U. Nath for helpful discussions and critical reading of this manuscript.

\section{LITERATURE CITED}

Bal, A., Hameed, S., and Jayaram, S. 1989. Ultrastructural characteristics of the host-symbiont interface in nitrogen-fixing peanut nodules. Protoplasma 150:19-26.

Boivin, S., Kazmierczak, T., Brault, M., Wen, J., Gamas, P., Mysore, K. S., and Frugier, F. 2016. Different cytokinin histidine kinase receptors regulate nodule initiation as well as later nodule developmental stages in Medicago truncatula. Plant Cell Environ. 39:2198-2209.

Boogerd, F. C., and Rossum, D. 1997. Nodulation of groundnut by Bradyrhizobium: A simple infection process by crack entry. FEMS Microbiol. Rev. 21:5-27.

Borghi, L., Gutzat, R., Futterer, J., Laizet, Y., Hennig, L., and Gruissem, W. 2010. Arabidopsis RETINOBLASTOMA-RELATED is required for stem cell maintenance, cell differentiation, and lateral organ production. Plant Cell 22:1792-1811.

Chandler, M. R. 1978. Some observations on infection of Arachis hypogaea L. by Rhizobium. J. Exp. Bot. 29:749-755

Charon, C., Johansson, C., Kondorosi, E., Kondorosi, A., and Crespi, M. 1997. enod40 induces dedifferentiation and division of root cortical cells in legumes. Proc. Natl. Acad. Sci. U.S.A. 94:8901-8906.

Cooper, J. B., and Long, S. R. 1994. Morphogenetic rescue of Rhizobium meliloti nodulation mutants by trans-zeatin secretion. Plant Cell 6: 215-225.

Crespi, M. D., Jurkevitch, E., Poiret, M., d'Aubenton-Carafa, Y., Petrovics, G., Kondorosi, E., and Kondorosi, A. 1994. enod40, a gene expressed during nodule organogenesis, codes for a non-translatable RNA involved in plant growth. EMBO J. 13:5099-5112.

Czernic, P., Gully, D., Cartieaux, F., Moulin, L., Guefreachi, I., Patrel, D., Pierre, O., Fardoux, J., Chaintreuil, C., Nguyen, P., Gressent, F., Da Silva, C., Poulain, J., Wincker, P., Rofidal, V., Hem, S., Barrière, Q., Arrighi, J.-F., Mergaert, P., and Giraud, E. 2015. Convergent evolution of endosymbiont differentiation in dalbergioid and inverted repeat-lacking clade legumes mediated by nodule-specific cysteine-rich peptides. Plant Physiol. 169:1254-1265.

Dello Ioio, R., Linhares, F. S., and Sabatini, S. 2008. Emerging role of cytokinin as a regulator of cellular differentiation. Curr. Opin. Plant Biol. 11:23-27.

Fabre, S., Gully, D., Poitout, A., Patrel, D., Arrighi, J. F., Giraud, E., Czernic, P., and Cartieaux, F. 2015. Nod factor-independent nodulation in Aeschynomene evenia required the common plant-microbe symbiotic toolkit. Plant Physiol. 169:2654-2664.

Franssen, H. J., Xiao, T. T., Kulikova, O., Wan, X., Bisseling, T., Scheres, B., and Heidstra, R. 2015. Root developmental programs shape the Medicago truncatula nodule meristem. Development 142:2941-2950.
Frugier, F., Kosuta, S., Murray, J. D., Crespi, M., and Szczyglowski, K. 2008. Cytokinin: Secret agent of symbiosis. Trends Plant Sci. 13:115-120.

Gleason, C., Chaudhuri, S., Yang, T., Munoz, A., Poovaiah, B. W., and Oldroyd, G. E. 2006. Nodulation independent of rhizobia induced by a calcium-activated kinase lacking autoinhibition. Nature 441:1149-1152.

Gonzalez-Rizzo, S., Crespi, M., and Frugier, F. 2006. The Medicago truncatula CRE1 cytokinin receptor regulates lateral root development and early symbiotic interaction with Sinorhizobium meliloti. Plant Cell 18:2680-2693.

González-Sama, A., de la Peña, T. C., Kevei, Z., Mergaert, P., Lucas, M. M. de Felipe, M. R., Kondorosi, E., and Pueyo, J. J. 2006. Nuclear DNA endoreduplication and expression of the mitotic inhibitor Ccs52 associated to determinate and lupinoid nodule organogenesis. Mol. Plant-Microbe Interact. 19:173-180.

Haynes, J. G., Czymmek, K. J., Carlson, C. A., Veereshlingam, H., Dickstein, R., and Sherrier, D. J. 2004. Rapid analysis of legume root nodule development using confocal microscopy. New Phytol. 163: 661-668.

Heckmann, A. B., Sandal, N., Bek, A. S., Madsen, L. H., Jurkiewicz, A., Nielsen, M. W., Tirichine, L., and Stougaard, J. 2011. Cytokinin induction of root nodule primordia in Lotus japonicus is regulated by a mechanism operating in the root cortex. Mol. Plant-Microbe Interact 24: 1385-1395

Held, M., Hou, H., Miri, M., Huynh, C., Ross, L., Hossain, M. S., Sato, S., Tabata, S., Perry, J., Wang, T. L., and Szczyglowski, K. 2014. Lotus japonicus cytokinin receptors work partially redundantly to mediate nodule formation. Plant Cell 26:678-694.

Javelle, M., Marco, C. F., and Timmermans, M. 2011. In situ hybridization for the precise localization of transcripts in plants. J. Vis. Exp. 57:e3328

Karimi, M., Inze, D., and Depicker, A. 2002. GATEWAY vectors for Agrobacterium-mediated plant transformation. Trends Plant Sci. 7: 193-195.

Lee, A., Lum, M. R., and Hirsch, A. M. 2007. ENOD40 gene expression and cytokinin responses in the nonnodulating, nonmycorrhizal (NodMyc-) mutant, Masym3, of Melilotus alba Desr. Plant Signal. Behav. 2:33-42.

Lefebvre, B., Timmers, T., Mbengue, M., Moreau, S., Hervé, C., Tóth, K. Bittencourt-Silvestre, J., Klaus, D., Deslandes, L., and Godiard, L. 2010 A remorin protein interacts with symbiotic receptors and regulates bacterial infection. Proc. Natl. Acad. Sci. U.S.A. 107:2343-2348.

Madsen, L. H., Tirichine, L., Jurkiewicz, A., Sullivan, J. T., Heckmann, A. B., Bek, A. S., Ronson, C. W., James, E. K., and Stougaard, J. 2010 The molecular network governing nodule organogenesis and infection in the model legume Lotus japonicus. Nat. Commun. 1: Article 10. doi: 10.1038/ncomms 1009

Marsh, J. F., Rakocevic, A., Mitra, R. M., Brocard, L., Sun, J., Eschstruth, A., Long, S. R., Schultze, M., Ratet, P., and Oldroyd, G. E. 2007. Medicago truncatula NIN is essential for rhizobial-independent nodule organogenesis induced by autoactive calcium/calmodulin-dependent protein kinase. Plant Physiol. 144:324-335.

Mathesius, U., Charon, C., Rolfe, B. G., Kondorosi, A., and Crespi, M 2000a. Temporal and spatial order of events during the induction of cortical cell divisions in white clover by Rhizobium leguminosarum bv. trifolii inoculation or localized cytokinin addition. Mol. Plant-Microbe Interact 13 : 617-628.

Mathesius, U., Weinman, J. J., Rolfe, B. G., and Djordjevic, M. A. 2000b. Rhizobia can induce nodules in white clover by "hijacking" mature cortical cells activated during lateral root development. Mol. Plant-Microbe Interact 13:170-182

Mergaert, P., Uchiumi, T., Alunni, B., Evanno, G., Cheron, A., Catrice, O., Mausset, A.-E., Barloy-Hubler, F., Galibert, F., and Kondorosi, A. 2006 Eukaryotic control on bacterial cell cycle and differentiation in the Rhizobium-legume symbiosis. Proc. Natl. Acad. Sci. U.S.A. 103:5230-5235.

Miri, M., Janakirama, P., Held, M., Ross, L., and Szczyglowski, K. 2016. Into the root: How cytokinin controls rhizobial infection. Trends Plant Sci. 21:178-186.

Mortier, V., Fenta, B. A., Martens, C., Rombauts, S., Holsters, M., Kunert, K., and Goormachtig, S. 2011. Search for nodulation-related CLE genes in the genome of Glycine max. J. Exp. Bot. 62:2571-2583.

Murray, J. D., Karas, B. J., Sato, S., Tabata, S., Amyot, L., and Szczyglowski, K. 2007. A cytokinin perception mutant colonized by Rhizobium in the absence of nodule organogenesis. Science 315:101-104.

Ng, J. L., Hassan, S., Truong, T. T., Hocart, C. H., Laffont, C., Frugier, F., and Mathesius, U. 2015. Flavonoids and auxin transport inhibitors rescue symbiotic nodulation in the Medicago truncatula cytokinin perception mutant cre1. Plant Cell 27:2210-2226.

Oldroyd, G. E. 2013. Speak, friend, and enter: Signalling systems that promote beneficial symbiotic associations in plants. Nat. Rev. Microbiol 11:252-263. 
Oono, R., and Denison, R. F. 2010. Comparing symbiotic efficiency between swollen versus nonswollen rhizobial bacteroids. Plant Physiol. 154:1541-1548.

Op den Camp, R. H., De Mita, S., Lillo, A., Cao, Q., Limpens, E., Bisseling, T., and Geurts, R. 2011. A phylogenetic strategy based on a legumespecific whole genome duplication yields symbiotic cytokinin type-A response regulators. Plant Physiol. 157:2013-2022.

Osipova, M. A., Mortier, V., Demchenko, K. N., Tsyganov, V. E., Tikhonovich, I. A., Lutova, L. A., Dolgikh, E. A., and Goormachtig, S. 2012. Wuschelrelated homeobox 5 gene expression and interaction of CLE peptides with components of the systemic control add two pieces to the puzzle of autoregulation of nodulation. Plant Physiol. 158:1329-1341.

Ovchinnikova, E., Journet, E.-P., Chabaud, M., Cosson, V., Ratet, P., Duc, G., Fedorova, E., Liu, W., den Camp, R. O., and Zhukov, V. 2011. IPD3 controls the formation of nitrogen-fixing symbiosomes in pea and Medicago spp. Mol. Plant-Microbe Interact. 24:1333-1344.

Perilli, S., Perez-Perez, J. M., Di Mambro, R., Peris, C. L., Díaz-Triviño, S., Del Bianco, M., Pierdonati, E., Moubayidin, L., Cruz-Ramírez, A., and Costantino, P. 2013. RETINOBLASTOMA-RELATED protein stimulates cell differentiation in the Arabidopsis root meristem by interacting with cytokinin signaling. Plant Cell 25:4469-4478.

Plet, J., Wasson, A., Ariel, F., Le Signor, C., Baker, D., Mathesius, U., Crespi, M., and Frugier, F. 2011. MtCRE1-dependent cytokinin signaling integrates bacterial and plant cues to coordinate symbiotic nodule organogenesis in Medicago truncatula. Plant J. 65:622-633.

Podlesakova, K., Fardoux, J., Patrel, D., Bonaldi, K., Novak, O., Strnad, M., Giraud, E., Spichal, L., and Nouwen, N. 2013. Rhizobial synthesized cytokinins contribute to but are not essential for the symbiotic interaction between photosynthetic bradyrhizobia and Aeschynomene legumes. Mol. Plant-Microbe Interact 26:1232-1238.

Popp, C., and Ott, T. 2011. Regulation of signal transduction and bacterial infection during root nodule symbiosis. Curr. Opin. Plant Biol. 14:458-467.

Reid, D. E., Heckmann, A. B., Novak, O., Kelly, S., and Stougaard, J. 2016. CYTOKININ OXIDASE/DEHYDROGENASE3 Maintains Cytokinin Homeostasis during Root and Nodule Development in Lotus japonicus. Plant Physiol. 170:1060-1074.

Saha, S., Dutta, A., Bhattacharya, A., and DasGupta, M. 2014. Intracellular catalytic domain of symbiosis receptor kinase hyperactivates spontaneous nodulation in absence of rhizobia. Plant Physiol. 166:1699-1708.

Saha, S., Paul, A., Herring, L., Dutta, A., Bhattacharya, A., Samaddar, S., Goshe, M. B., and DasGupta, M. 2016. Gatekeeper tyrosine phosphorylation of SYMRK is essential for synchronizing the epidermal and cortical responses in root nodule symbiosis. Plant Physiol. 171:71-81.

Saitou, N., and Nei, M. 1987. The neighbor-joining method: A new method for reconstructing phylogenetic trees. Mol. Biol. Evol. 4:406-425.

Sarkar, A. K., Luijten, M., Miyashima, S., Lenhard, M., Hashimoto, T., Nakajima, K., Scheres, B., Heidstra, R., and Laux, T. 2007. Conserved factors regulate signalling in Arabidopsis thaliana shoot and root stem cell organizers. Nature 446:811-814.

Saur, I. M., Oakes, M., Djordjevic, M. A., and Imin, N. 2011. Crosstalk between the nodulation signaling pathway and the autoregulation of nodulation in Medicago truncatula. New Phytol. 190:865-874.

Singh, S., Katzer, K., Lambert, J., Cerri, M., and Parniske, M. 2014. CYCLOPS, a DNA-binding transcriptional activator, orchestrates symbiotic root nodule development. Cell Host Microbe 15:139-152.

Sinharoy, S., and DasGupta, M. 2009. RNA interference highlights the role of CCaMK in dissemination of endosymbionts in the Aeschynomeneae legume Arachis. Mol. Plant-Microbe Interact 22:1466-1475.
Sinharoy, S., Saha, S., Chaudhury, S. R., and Dasgupta, M. 2009. Transformed hairy roots of Arachis hypogea: A tool for studying root nodule symbiosis in a non-infection thread legume of the Aeschynomeneae tribe. Mol. PlantMicrobe Interact 22:132-142.

Smit, P., Raedts, J., Portyanko, V., Debelle, F., Gough, C., Bisseling, T., and Geurts, R. 2005. NSP1 of the GRAS protein family is essential for rhizobial Nod factor-induced transcription. Science 308:1789-1791.

Sprent, J. I., and James, E. K. 2007. Legume evolution: Where do nodules and mycorrhizas fit in? Plant Physiol. 144:575-581.

Suzaki, T., Yano, K., Ito, M., Umehara, Y., Suganuma, N., and Kawaguchi, M. 2012. Positive and negative regulation of cortical cell division during root nodule development in Lotus japonicus is accompanied by auxin response. Development 139:3997-4006.

Takatsuka, H., and Umeda, M. 2014. Hormonal control of cell division and elongation along differentiation trajectories in roots. J. Exp. Bot. 65:2633-2643.

Tamura, K., Peterson, D., Peterson, N., Stecher, G., Nei, M., and Kumar, S. 2011. MEGA5: Molecular evolutionary genetics analysis using maximum likelihood, evolutionary distance, and maximum parsimony methods. Mol. Biol. Evol. 28:2731-2739.

Tirichine, L., Imaizumi-Anraku, H., Yoshida, S., Murakami, Y., Madsen, L. H., Miwa, H., Nakagawa, T., Sandal, N., Albrektsen, A. S., Kawaguchi, M., Downie, A., Sato, S., Tabata, S., Kouchi, H., Parniske, M., Kawasaki, S., and Stougaard, J. 2006. Deregulation of a Ca2+/calmodulin-dependent kinase leads to spontaneous nodule development. Nature 441:1153-1156.

Tirichine, L., Sandal, N., Madsen, L. H., Radutoiu, S., Albrektsen, A. S., Sato, S., Asamizu, E., Tabata, S., and Stougaard, J. 2007. A gain-offunction mutation in a cytokinin receptor triggers spontaneous root nodule organogenesis. Science 315:104-107.

To, J. P., Deruere, J., Maxwell, B. B., Morris, V. F., Hutchison, C. E., Ferreira, F. J., Schaller, G. E., and Kieber, J. J. 2007. Cytokinin regulates type-A Arabidopsis response regulator activity and protein stability via two-component phosphorelay. Plant Cell 19:3901-3914.

Torrey, J. G., and Barrios, S. 1969. Cytological studies on rhizobial nodules initiation in Pisum. Caryologia 22:47-61.

Toth, K., Stratil, T. F., Madsen, E. B., Ye, J., Popp, C., Antolin-Llovera, M., Grossmann, C., Jensen, O. N., Schussler, A., Parniske, M., and Ott, T. 2012. Functional domain analysis of the Remorin protein LjSYMREM1 in Lotus japonicus. PLoS One 7:e30817.

Truchet, G. 1978. Sur l'état diploide des cellules du méristème des nodules radiculaires des légumineuses. Ann. Sci. Nat. Bot 19:3-38.

van Zeijl, A., Op den Camp, R. H., Deinum, E. E., Charnikhova, T., Franssen, H., Op den Camp, H. J., Bouwmeester, H., Kohlen, W., Bisseling, T., and Geurts, R. 2015. Rhizobium lipo-chitooligosaccharide signaling triggers accumulation of cytokinins in Medicago truncatula roots. Mol. Plant 8:1213-1226.

Verdeil, J. L., Alemanno, L., Niemenak, N., and Tranbarger, T. J. 2007. Pluripotent versus totipotent plant stem cells: Dependence versus autonomy? Trends Plant Sci. 12:245-252.

Vernie, T., Moreau, S., de Billy, F., Plet, J., Combier, J. P., Rogers, C., Oldroyd, G., Frugier, F., Niebel, A., and Gamas, P. 2008. EFD Is an ERF transcription factor involved in the control of nodule number and differentiation in Medicago truncatula. Plant Cell 20:2696-2713.

Yano, K., Yoshida, S., Müller, J., Singh, S., Banba, M., Vickers, K., Markmann, K., White, C., Schuller, B., and Sato, S. 2008. CYCLOPS, a mediator of symbiotic intracellular accommodation. Proc. Natl. Acad. Sci. U.S.A. 105:20540-20545.

Zhang, W., Swarup, R., Bennett, M., Schaller, G. E., and Kieber, J. J. 2013. Cytokinin induces cell division in the quiescent center of the Arabidopsis root apical meristem. Curr. Biol. 23:1979-1989. 